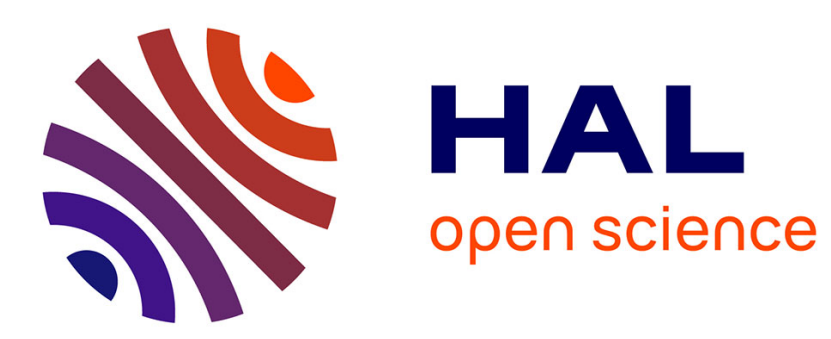

\title{
Self Control and Intertemporal Choice: Evidence from Glucose and Depletion Interventions
}

\author{
Michael A. Kuhn, Peter Kuhn, Marie Claire Villeval
}

\section{To cite this version:}

Michael A. Kuhn, Peter Kuhn, Marie Claire Villeval. Self Control and Intertemporal Choice: Evidence from Glucose and Depletion Interventions. 2014. halshs-00954539

\section{HAL Id: halshs-00954539 \\ https://shs.hal.science/halshs-00954539}

Submitted on 3 Mar 2014

HAL is a multi-disciplinary open access archive for the deposit and dissemination of scientific research documents, whether they are published or not. The documents may come from teaching and research institutions in France or abroad, or from public or private research centers.
L'archive ouverte pluridisciplinaire $\mathbf{H A L}$, est destinée au dépôt et à la diffusion de documents scientifiques de niveau recherche, publiés ou non, émanant des établissements d'enseignement et de recherche français ou étrangers, des laboratoires publics ou privés. 

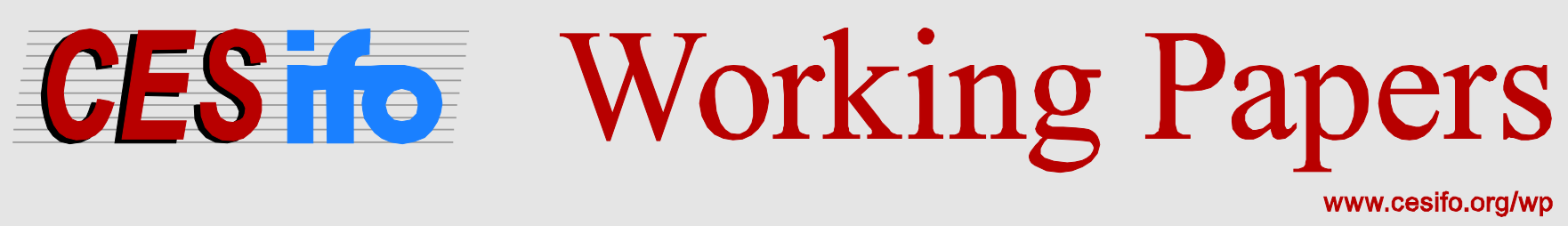

\title{
Self Control and Intertemporal Choice: Evidence from Glucose and Depletion Interventions
}

\author{
Michael A. Kuhn \\ Peter Kuhn \\ Marie Claire Villeval
}

CESIFO WORKING PAPER NO. 4609

CATEGORY 13: BEHAVIOURAL ECONOMICS

JANUARY 2014

An electronic version of the paper may be downloaded

- from the SSRN website:

- from the RePEc website:

- from the CESifo website:

WWW.SSRN.com

www.RePEc.org

www.CESifo-group.org/wp

\section{CESifo}




\title{
Self Control and Intertemporal Choice: Evidence from Glucose and Depletion Interventions
}

\begin{abstract}
Recent developments in economic theory model intertemporal choice decisions as problems of restraining one's natural impulse to consume today. We use interventions that have been shown in the psychology literature to affect impulse control to examine whether this is indeed the case for laboratory elicitations of time preference. In other words, is savings behavior affected by manipulations of willpower? Our results are mixed, with one widely used willpower-reducing intervention increasing subjects' savings, and with evidence of a substantial placebo effects with respect to another intervention based on sugared beverage consumption. Since all our treatment effects -which are substantial in magnitude- are driven by increases in the intertemporal substitution elasticity (i.e. greater sensitivity to high prices), we suspect that the primary mechanism behind them is an increase in subjects' attention to the decision, rather than their ability to resist the temptation to get money sooner.
\end{abstract}

JEL-Code: C910, D900.

Keywords: time preferences, self-control, depletion, sucrose, experiment.

Michael A. Kuhn
University of California at San Diego
Department of Economics
9500 Gilman Drive
USA - La Jolla, CA 92093
mkuhn@ucsd.edu
Peter Kuhn
University of California at Santa Barbara
Department of Economics
USA - Santa Barbara, CA 93106 Claire Villeval
pjkuhn@econ.ucsb.edu

July 11, 2013

This research has been supported by a grant from the French National Research Agency (ANR, EMCO program, HEIDI grant) and was performed within the framework of the LABEX CORTEX (ANR-11-LABX-0042) of Université de Lyon, withing the program "Investissements d'Avenir" (ANR-11-IDEX-007) operated by the French National Research Agency (ANR). We thank James Andreoni and Charles Sprenger for valuable feedback and participants at the BLUE workshop at the University of Edinburgh and at the ASFEE conference in Lyon, for useful comments. 


\section{Introduction}

Models of willpower, temptation and self control are now commonplace in economics. They all aim to capture the visceral push-pull relationship between temptation and prudence that seems a natural way to conceptualize intertemporal choice situations. Decision makers are modeled as two conflicting selves (Shefrin and Thaler 1988; Bernheim and Rangel 2004; Fudenberg and Levine 2006) or as receiving extra utility when gratification is immediate (Laibson 1997; O'Donoghue and Rabin 1999). Ozdenoren, Salant and Silverman (2012) explicitly model willpower as a depletable resource. But how relevant is this modeling approach to fundamental economic behaviors such as borrowing and saving money? By implementing interventions identified by the psychology literature as shifters of willpower, our goal in this paper is to ask whether a willpower-based theoretical paradigm is consistent with across-treatment comparative statics in an abstract borrowing/saving environment.

Psychological research suggests that willpower -the ability to control the self and refrain from impulsive or short-sighted decisions- is negatively affected by prior performance of a task that also requires impulse control. Both dieters who are exposed to the sight of tempting snacks, and those who are asked to suppress their emotional responses while watching an emotional video, subsequently consume more ice cream than dieters engaged in tasks not requiring impulse control (Vohs and Heatherton 2000). Subjects who were asked to suppress an irrelevant thought for ten minutes subsequently had greater difficulty resisting alcohol than subjects who performed arithmetic for the same amount of time (Muraven, Collins and Nienhaus 2002). ${ }^{1}$ Cognitive load has been found to increase impulsiveness (Hinson, Jameson and Whitney 2003). Similar effects have been found for performance on a wide variety of self-control tasks. ${ }^{2}$ Muraven and Baumeister (2000) argue that these results are consistent with a resource-depletion model of self-control: “... controlling one's own behavior requires the expenditure of some inner, limited resource that is depleted afterward." (p.247).

More recently, a number of investigators have argued that blood glucose -which constitutes the

\footnotetext{
${ }^{1}$ Similar studies of the effects of willpower depletion -manipulated in a variety of ways- on subjects' management of food and alcohol consumption include Kahan, Polivy and Herman (2003), Muraven et al. (2005) and Baumeister et al. (1998).

${ }^{2}$ These include resisting opportunities to cheat the experimenter for financial gain (Mead et al. 2009), suppressing stereotypes and prejudice (Gordijn et al. 2004; Richeson and Shelton, 2003; Richeson and Trawalter, 2005; Richeson, Trawalter, and Shelton, 2005) and restraining aggression (DeWall et al., 2007; Stucke and Baumeister, 2006).
} 
body's primary source of energy- is the limited resource that is depleted by acts of self-regulation. In a series of experiments, Gailliot et al. $(2007,2009)$ find that engaging in self-control reduces measured levels of blood glucose, that these induced low glucose levels predict poor performance on a variety of subsequent self-control tasks, and that consumption of a drink sweetened with sucrose (relative to an artificially-sweetened drink) mitigates these poor performance levels. ${ }^{3}$ Effects of sucrose consumption have been demonstrated on outcomes including inflicting pain on others, and the use of racial stereotypes and slurs. ${ }^{4}$

Motivated by the parallels between the psychology experiments and economic theory, this paper considers whether depletion of impulse control and sucrose consumption affect a fundamental aspect of economic behavior: the allocation of income over time. While it might be tempting to view intertemporal allocation decisions as simply a case of resisting an impulse to consume more sooner, it is not at all clear that factors that affect actions like using racial stereotypes or inflicting pain on others will affect financial decisions at all, or in the same way. Adapting the Convex Time Budget technique developed by Andreoni and Sprenger (2012) we allow participants in a laboratory experiment to make a series of choices about payments they will receive sooner or later, across conditions related to willpower depletion and sugar consumption. A contribution of our paper is to identify which dimensions of a widely used intertemporal utility function -specifically the discount rate, present bias and intertemporal elasticity of substitution- are affected by our treatment manipulations. Because our procedure allows us to recover the structural parameters this intertemporal utility function for each subject in our sample, we can translate the abstract concept of willpower into quantitative statements that are relevant to decisions like mortgage refinancing, retirement planning, payday advances and human capital investments.

We find that time preferences are sensitive to both our interventions, but we do not find that willpower depletion makes subjects less patient. ${ }^{5}$ Instead, participants who have been exposed to a widely-used willpower-depleting task -the Stroop (1935) test- exhibit increased patience in the subsequent time preference elicitation. We also find that fasted participants given a sugared

\footnotetext{
${ }^{3}$ Glucose is absorbed into the bloodstream at a rate of 30 calories per minute. Metabolization to the brain typically occurs within ten minutes (Donohoe and Benton 1999).

${ }^{4}$ See Gailliot and Baumeister (2007) for a review of this literature.

${ }^{5}$ Throughout this paper we use 'patience' as convenient shorthand for a tendency to delay the receipt of income, holding other conditions (prices, amount of delay), constant. Since 'patience' is sometimes also used, more specifically, to refer to an absence of present bias in a structural model of choice, we will be explicit whenever we discuss present bias per se.
} 
beverage prior to the time preference elicitation are more patient, but that a placebo beverage produces a similar, albeit less powerful, effect. All these effects are economically significant in magnitude, corresponding to large differences in demand for short-term loans.

Our structural estimates indicate that the clear majority of the effect of all of our treatments (whether depletion, sugared drink or placebo drink) is not on the subjective discount rate or present bias parameters, but on the intertemporal elasticity of substitution. Essentially, while subjects in all treatments choose the same level of early income when early income is cheap, treated subjects are much more likely to reduce their early income when its relative price rises. This suggests a model in which all our treatments increase the amount of attention subjects devote to the intertemporal allocation decision. ${ }^{6}$ This is consistent with Chabris, Laibson and Schuldt's (2008) observation that when subjects in experiments such as ours are considering their extra-laboratory options, their choices should only reveal their available borrowing or saving rates. As such, subjects paying close attention to the relationship of the lab options to the broader credit market should yield linear time preference estimates (because of the arbitrage opportunities). An attention-based interpretation of our results also seems consistent with our finding that all our treatment effects vanish in a subsample with very high cognitive abilities; these subjects exhibit the same (high) level of pricesensitivity regardless of how we treat them.

While our experimental environment is highly abstract, we are encouraged by the fact that a number of economic studies in context-rich environments suggest that attention is a key factor in decision quality. Carroll et al. (2009) show that simply manipulating the default savings plan is a powerful tool for increasing individual savings, indicating limited attentiveness to the decision. They also find that forcing an active choice improves choices. The common thread linking this literature, our results and the economic theory is that the temptation individuals face has much more to do with the time and effort needed to make the right decision than the actual utility ramifications of their choices, which in our experiment -and in most existing experiments on intertemporal choices- are likely small. ${ }^{7}$

The remainder of this paper is organized as follows. Section 2 briefly considers the related

\footnotetext{
${ }^{6}$ Koszegi and Szeidl (2013) model the effects of attention on intertemporal choices and argue that models with limited attention can explain a number of anomalies and stylized facts concerning intertemporal choice patterns.

${ }^{7}$ For direct evidence that willpower-based models of intertemporal choice are more relevant for the exertion of effort than financial choice, see Augenblick, Niederle and Sprenger (2012).
} 
literatures. Section 3 details the experimental design. We present our data analysis in Section 4 while Section 5 discusses our results and concludes.

\section{Related Literature}

In addition to the psychological literature on willpower and economists' theoretical models of self-control discussed above, our paper contributes to four literatures. One of these is a small empirical literature in economics on the effects of willpower depletion and nutrition on choices and effort. Concerning willpower depletion, Bucciol, Houser and Piovesan (2011) demonstrate that productivity of younger children in a simple craft task is negatively affected by prior exposure to consumption temptation. Suggestive of our own findings, Burger, Charness and Lynham (2011) showed that the same depletion task used on our paper -the Stroop (1935) task-improves long-run task completion rates in a procrastination study. Concerning nutrition, a small labor economics literature studies the effects of breakfast programs in schools. For example, Dotter (2013) uses a natural experiment to show that universally-free breakfast programs have large positive effects on both math and reading scores. ${ }^{8}$

Second is a literature on the both the direct and mediating effects of cognitive ability economic decisions, including those involving time preference. For example, strong correlations have been found between childrens' ability to resist temptation in the famous marshmallow experiment (Mischel, Ebbesen and Raskoff Zeiss 1972) and a variety of cognitive outcomes, including SAT scores (Shoda, Mischel and Peake 1990), IQ (Funder and Block 1989) and college GPA (Kirby, Winston and Santiesteban 2005). Other studies that have linked intelligence with discounting include Frederick (2005), Dohmen et al. (2010) and Shamosh and Gray's (2008) meta-analysis. In a large-scale experiment with trainee truckers, Rustichini et al. (2012) also establish that time preferences are influenced by cognitive ability, while Benjamin, Brown and Shapiro (2013) link "anomalous time preferences" with lower cognitive ability.

Methodologically, this paper contributes to two budding experimental literatures. The first is the measurement of time preferences. We modify the Convex Time Budget technique of Andreoni

\footnotetext{
${ }^{8}$ Foundational to this study is Wesnes et al. (2003), which finds that breakfast interventions do increase attention and memory. Notably, a glucose drink alone increased the speed at which items could be retrieved from memory for 90 minutes following consumption.
} 
and Sprenger (2012) by first identifying the annual interest rates of relevant market options to our subject pool, and then calibrating the budgets we offer to detect differences in discounting over this exact range. Our results showcase estimates in the heart of this range. Additionally, our experiment is one of very few that is designed explicitly to examine treatment effects on the parameters of structural model. Callen et al. (2013) and Carvalho, Prina and Sydnor (2013) do so with risk preferences and violent trauma and time preferences and savings accounts respectively. This technique can provide a deeper understanding of the treatment effects in question, allows for more flexible policy analysis and if designed properly, permits standard reduced-form analysis as well.

The two most closely related papers to ours are Ifcher and Zarghamee (2011) and Wang and Dvorak (2010), who respectively find that experimenter-induced positive affect and sucrose consumption lead to more patient choices between money received today versus later. In addition to Ifcher and Zarghamee's focus on a different intervention than us (and the fact that neither paper studies the effects of a willpower-depleting activity), the key differences between our study and both these analyses are our ability to study placebo effects (by comparing the sugar-free drink to no drink); a time-preference elicitation procedure that allows us to distinguish treatment effects on discounting, present bias and price-sensitivity; and our analysis of the mediating effect of cognitive ability. Together, these aspects of our approach provide important additional information regarding the mechanisms behind all our treatment effects.

In particular, the patience-enhancing effects of consuming a sugar-free drink -which turn out to be larger than the additional effect of the sugared drink-suggest important effects of the immediate choice environment on patience that are unrelated to blood glucose. In addition, the finding that all our main treatment effects operate not on discounting or present bias but on price sensitivity, combined with the mediating role of cognitive ability, suggests that the dominant mechanism which we argue involves attention- may be quite different from those implied by risk-sensitive foraging theory (Stephens and John 1986), or models based on self-regulatory strength (Gaillot $e t$ al. 2007). ${ }^{9}$

\footnotetext{
${ }^{9}$ Wang and Dvorak argue that their findings are consistent with risk-sensitive foraging theory, which posits that sugar-induced increases in the body's energy budget should induce organisms to be more future-oriented to increase the chance of reproductive success.
} 


\section{The Experiment}

\subsection{Treatments}

Our experiment consists of three types of sessions: Baseline, Depletion and Drink. Within each session type, there are five distinct parts, the orders of which change across session type. In a Drink session, the phases are: (1) consumption of drink and entry questions, (2) rest to allow any sucrose in the drink to be metabolized into blood glucose, (3) elicitation of time preferences, (4) depletion of self-control in the Stroop test, and (5) an exit survey that includes Frederick's (2005) Cognitive Reflection Test (CRT). The structure of the Baseline sessions is similar to that of Drink sessions, except that no beverage is given. In Depletion sessions, we invert the order between the Stroop test and the elicitation of time preferences. Finally, within the Drink sessions, we have two conditions corresponding to a drink containing sugar or a sugar-substitute. These variations give us four treatments: Baseline, Depletion, Placebo and Sugar. Table 1 lays out the progression of the experiment for each treatment.

\section{Table 1 about here}

The comparison between the Depletion treatment and the Baseline allows us to determine whether performing an initial task that requires impulse control affects the decision to defer income in the time preference task. The comparison between the Sugar treatment and the Placebo treatment allows us to study whether the consumption of sugar affects time preferences. Finally, if time preferences react to the consumption and metabolization of sucrose rather than the drink itself, we expect to observe no differences in choices when comparing the Placebo treatment and the Baseline. We discuss each task and drink consumption in more detail below.

\subsection{Time Preference Elicitation}

To elicit time preferences, we implement the Convex Time Budget (CTB) method of Andreoni and Sprenger (2012, henceforth AS). This approach allows us to estimate individual-specific preference parameters.

In every choice, participants received a budget of 16 tokens to allocate between an early payment, $c_{t}$, and a late payment, $c_{t+k}$, with $t$ the early payment date and $k$ the delay between the two 
dates. Participants made 45 allocation decisions and one of these decisions was randomly selected at the end of the session for actual payment according to the allocation of tokens between the two dates. The 45 budgets combine three early payment dates $(t=0,5,15$ weeks), three delay lengths ( $k=5,10,15$ weeks) and various price ratios. Thus, there were only seven paydays evenly spaced at five weeks intervals $(0,5,10,15,20,25,30$ weeks $)$. For each $(t, k)$ combination, participants had to make five decisions involving various interest rates. We defined three rate progressions that were combined with the various early payment dates while the combination of budget progressions and delay lengths were kept constant. The value of a token at the late date, $a_{t+k}$, was always equal to $€ 1$, while the value of the token at the early date, $a_{t}$, varied between a minimum of $€ 0.67$ and a maximum of $€ 0.99$. Allocating all the tokens to the late payment date paid $€ 16$; allocating all the tokens to the early payment date paid a minimum of $€ 10.72$ and a maximum of $€ 15.84$. The progressions were defined in order to offer implied annual interest rates, compounded quarterly, between $4 \%$ and $845 \%$. Table A1 in the Appendix presents all the choice sets.

The presentation of the 45 decisions was very similar to that in AS. A choice screen had nine decision tabs that were displayed successively and corresponded to the nine $(t, k)$ combinations. The order between the nine tabs was randomly and independently determined for each participant to control for order effects. Each decision tab displayed five budget decisions presented in order of increasing gross interest rate. To facilitate decision-making by a better visualization of delays, each decision tab displayed a dynamic calendar highlighting the current date, the early date and the late date in different colors. It also displayed the values of a token at the early date and at the late date, together with the values in Euros of the earnings corresponding to the decisions. A sample decision tab is reproduced in the Appendix. The boxes for entering the allocation decisions were initially blank. As soon as a value was entered either for the early date or the late date, the other box was filled automatically to ensure that the total budget was 16 tokens and the corresponding payoffs in Euro at the two dates were also displayed.

This design allows us to estimate for each individual her discount rate, the curvature of her utility function (through the variations of $k$ and of the gross interest rate), and her present bias and hyperbolic discounting (through the variation of $t$ ). In addition, it allows us to examine which, if any, of these dimensions is impacted by self-control depletion and sucrose consumption. 


\subsection{Willpower Depletion}

We used a Stroop test (Stroop, 1935) to deplete self-control as shown by studies in social psychology (for a survey of the test, see MacLeod 1991). In a typical Stroop test, individuals have to read the color of ink used to write words independently of the color names of words. In some trials, there is congruence between the color of the word and the color of the ink (the word "yellow" is written in yellow) but in other trials there is no congruence (the word "yellow" is written in red and the correct answer is red). The incongruent stimuli typically require more time and produce more mistakes than the congruent stimuli because the brain automatically decodes the semantic meaning of the word and needs to override its first reaction to identify the color of the ink. Shortcutting the automatic process requires self-control.

In our experiment, the participants' computer screen displayed a series of color words (black, blue, yellow, green and red) successively, and the participants were instructed to indicate, as quickly and accurately as possible, the ink color in which the word was written. The list of possible colors was displayed at the bottom of the screen and the participants had to press the button corresponding to the color of the ink, whether or not that matched the color name of the word (see instructions in Appendix). They had to complete congruent and incongruent Stroop trials in random order for 6 minutes. On average they completed 126 trials (S.D. =11.69). As expected, the time spent on incongruent words was significantly higher than on the congruent words (two-tailed t-test, $p<0.001)$.

\subsection{Drink Consumption}

Following Gailliot et al. (2007), participants in each Drink session were given 14 ounces (40 centiliters) of a soft drink sweetened either with sugar or with a sugar substitute. Both types of drinks had the same appearance. The sugared drink contained 158 kilocalories and the placebo drink contained $10 .^{10}$ We used a double blind procedure to administer the drinks: neither the participants nor the experimenters were aware of the sugar content of the beverage.

After being invited to drink the beverage, participants could rest in silence and read magazines

\footnotetext{
${ }^{10}$ Specifically, the drinks were Fanta "Citron frappé" and Fanta Zero "Citron frappé". They were dispensed in glasses (not the original container) and appear identical (see Figure A1 in the Appendix). Neither contains caffeine, though both contain ascorbic acid (vitamin C).
} 
that we distributed during 10 minutes in order to allow the sucrose to be metabolized into glucose. Three minutes before the end of this period, participants had to assess the beverage and to report their usual consumption of soft drinks. ${ }^{11}$ In the Baseline and the Depletion treatment, the same rest period of 10 minutes was implemented.

\subsection{Procedures}

The experiment was computerized, using the REGATE-NG software. It consisted of 8 sessions conducted at the laboratory of the GATE (Groupe d'Analyse et de Théorie Economique) institute in Lyon, France. Undergraduate students from the local engineering and business schools were invited via the ORSEE software (Greiner 2004). Between 17 and 20 participants took part in each session, for a total of 149 participants. Two sessions of the Baseline treatment were implemented with a total of 34 participants; two sessions of the Depletion treatment were implemented involving 40 participants; and four Drink sessions were implemented with 75 participants (37 in the sugar condition and 38 in the placebo condition).

The invitation message addressed to the participants of all treatments indicated that they may possibly have to drink a beverage containing sugar during the session and that individuals suffering or thinking that they may suffer from a pathology linked to blood glucose regulation (like diabetes) should abstain from participating. After signing up, all the participants in all the treatments were instructed not to drink or eat at least three hours prior to the beginning of the session in order to stabilize blood glucose levels. Upon arrival we recorded the time of their last intake. Since chronobiology may influence economic decision-making (see Dickinson and McElroy, 2010), all the sessions were run at noon, when the level of blood glucose is low. ${ }^{12}$

Upon arrival, the participants had to sign a consent form reminding them that they should not participate if they suffer from a disease related to failure of blood sugar regulation. Then participants randomly drew a tag from a bag assigning them to a terminal. The instructions for

\footnotetext{
${ }^{11}$ The questions were: 1) Please rate your enjoyment of the beverage you just consumed, between 1 and 10.2 ) How many calories do you think the beverage contained? 3) How often do you drink soft drinks (Coke, Pepsi, lemonade, ...): every day / every week / once or twice a month or less / less than twice a month? Although participants in the Placebo condition assessed the beverage less positively (mean $=4.55$, S.D. $=2.77$ ) than those in the Sugar condition $($ mean $=5.57$, S.D. $=2.58)($ two-tailed Mann-Whitney test, $p=0.097)$, they did not realize that they received a placebo. Indeed, they predicted the same number of calories contained in the beverage (mean =124.16, S.D. $=86.26)$ than the participants placed in the Sugar condition (mean $=140.41$, S.D. $=98.26)(p=0.497)$.

${ }^{12}$ We did not measure individuals' baseline blood glucose level, which would have required taking blood samples.
} 
each segment were distributed and read aloud by the experimenter after the completion of the prior segment (see Appendix).

The elicitation of time preferences requires very strict procedural rules. To participate in the experiment, the students were required to own a personal bank account and were informed by the invitation message that they would be paid by a wire transfer to their bank account; they were required to bring us a bank statement. ${ }^{13}$ During the session, instructions informed the participants that a show-up fee of $€ 5$ (\$6.5) would be wired to their bank account in addition to their other payoffs at two different dates, regardless of their decisions: half of the show-up fee amount would be paid at the early date and the other half at the late date indicated by the decision randomly selected at the end of the session for payment. The show-up fee had no differential influence on the 45 allocation decisions. Participants were also informed that the dates mentioned on the decision screens were the dates at which the wire transfers would be ordered by the finance department. ${ }^{14}$ To maximize the confidence of the participants about the payment of their earnings, they received a document stating that the bank transfer would be ordered by the National Center for Scientific Research (CNRS). ${ }^{15}$ In addition, the document mentioned the name, email address and phone number of the professor in charge of the experiment who could be contacted in case of any problem with the payment.

At the end of each session, participants received a feedback on the decision randomly selected for payment, indicating their payoffs and the dates of the two wire transfers for this decision. Then, they had to complete an exit survey which included questions about their demographics and average mark on the final high school exam (Baccalauréat). Sessions lasted 60 minutes and participants averaged earnings of $€ 20.43$ (\$26.62, with a standard deviation of $€ 0.97$ (\$1.26), including the show up fee.

\footnotetext{
${ }^{13}$ We cannot rule out that the information given in the message (payment wired to the bank account and possibility of having to drink a beverage) has led to a self-selection of participants. However, the sessions were booked as quickly as usual. In addition, we asked 44 students participating in another experiment with standard cash payment whether they owned a personal bank account; all of them answered positively. Moreover, there is no reason to believe that the two criteria for participating were correlated. Finally, the message did not mention that the payment could be made at two different dates which could have generated some self-selection.

${ }^{14}$ The administration committed to respect exactly the dates of the transfers and sent us a feedback after each payment. We believe the transaction costs associated with this payment methodology are lower than the typical approach used in this type of experiment, which relies on personal checks or vouchers.

${ }^{15}$ In France, CNRS is a well-known science and technology public agency. It employs 25,000 people and it operates through 1,235 research institutes. Students are aware that the GATE institute is operated by both the CNRS and the University of Lyon.
} 


\section{Results}

We present our results in four sections. The first section establishes a number of basic patterns in a pooled sample of all treatments, to provide context for the study of treatment effects. The second and third sections are nonparametric and structural approaches to analyzing the treatment effects, respectively. The final section presents some robustness checks. Since one of our central questions is how the impact of treatment manipulation on patience is mediated by the subjects' cognitive ability, and since a large share of our subjects has very high cognitive skills relative to the French population, we present most of our experimental results separately according to our subjects' reported achievement on the French Baccalauréat exam. ${ }^{16}$ To maximize statistical power, we simply divide our participants in half relative to the median score in our sample, which was 16. Importantly, because only 9\% of French Baccalaurat recipients earned a score of 16 or higher (our participants are drawn from selective universities), we refer to our two groups as "high score" and "lower score" respectively. Our high-scoring subjects clearly represent an elite level (about the top decile) of achievement among French high school graduates, while our lower-scoring group roughly represents the 50th through 90th percentiles. Thus the results for our lower-scoring group are more representative of a typical high school graduate in France, and we focus much of our discussion on that group. ${ }^{17}$

\subsection{Overall Features of Behavior}

We start by presenting two foundational results that verify aspects of our model and design, plus some simple descriptive statistics for the pooled sample across all treatments. The first result is that subjects' aggregate demand curves in the experiment satisfy two general predictions of utilitymaximizing intertemporal behavior.

Result 1 - Consistent with predictions for agents who discount the future and have some preference curvature, mean demand for early income exceeds half the 16-token endowment at interest

\footnotetext{
${ }^{16}$ The French Baccalauréat exam (le bac) is taken at the end of high school (lycée). In 2012, slightly over three quarters of French youth had passed the Baccalauréat.

${ }^{17}$ The results of the Cognitive Reflection Test (CRT) performed at the end of the sessions are highly correlated with Baccalauréat score, and we can replicate all our main results using this measure of cognitive ability as well. However since subjects' CRT results could be affected by our treatments, we focus on the Baccalauréat-score based results.
} 
rates near zero, then declines monotonically with the price of early income. This behavior characterizes both high- and lower-score participants.

A simple but general model of choice between early and late tokens for any combination of early payment date $(\mathrm{t})$ and delay $(\mathrm{k})$ supposes that subjects solve

$$
\max _{X, Y} U(X)+\lambda U(Y), \quad \text { subject to } \quad R X+Y \leq M
$$

where $X$ is experimental income received in the early period, $Y$ is experimental income received in the later period, $U^{\prime}>0, U^{\prime \prime}<0, R$ is the price of sooner income, and $M$ is the endowment. In (1), $\lambda<1$ can depend on both $t$ and $k$ to incorporate both discounting and present bias, but is fixed within any $(t, k)$ cell. $R$, on the other hand, varies within a $(t, k)$ cell as we experimentally manipulate the implied interest rate. For this model of preferences, Figure 1 illustrates (a) that subjects should consume more than half their endowment in the early period $(X>8)$ when $R=1$ because $\lambda<1$, and that $X$ should fall monotonically as $R$ rises because income and substitution effects reinforce each other when the endowment is all in the later period, as is the case in our experiment. ${ }^{18}$

Figure 1 about here

Both these predictions are confirmed by the evidence in Figure 2, which plots the demand curves for the early payment $(X)$, separately by score and pooled across all treatments. With the exception of the shortest delay length and latest start date for both groups, the demand curves all start at above eight units of $X$ at levels of $R$ closest to one, then fall monotonically as $R$ rises. ${ }^{19}$ The success of these basic predictions suggests that our participants' choices are informative for the preferences we wish to study.

\footnotetext{
${ }^{18}$ Alert readers will note that equation (1) models demand for early versus late experimental payments in the same way economists typically model intertemporal consumption choices. Of course, if subjects choose total consumption according to (1) but have access to perfect capital markets, their demand for experimental payments will consist of corner solutions (i.e. either $X=0$ or $Y=0$ ) that maximize the market value of experimental payments. Effectively, subjects would behave as if the $U$ function had little or no curvature. We test this idea formally in Section 4.3 and argue that it may shed some light on the possible mechanisms behind our estimated treatment effects.

${ }^{19}$ Because we do not observe choices from a zero-interest budget and Figure 2 indicates substantial non-linearity in the demand curves, we used our structural model to estimate choices at $R=1$ to further test the prediction about income levels when $R=1$. We found strong support, for all combinations of delay length and whether the early payment occurs immediately. The minimum predicted zero-interest demand is $€ 9.32($ S.E. $=0.25)$.
} 
Figure 2 about here

Result 2 - There is evidence of small but significant present bias in our data, among both highand lower-test score participants.

Participants receive the first of their two payments either on the day of the experiment, 5 weeks after the experiment or 15 weeks after the experiment. To test formally for present bias we regress early payments on dummy variables for $t=5$ and $t=15$ as well as the price ratio while clustering standard errors at the individual level. ${ }^{20}$ Table 2 presents the results of these regressions. If the date of first payment is immediate rather than 5 or 15 weeks in the future, lower-score subjects borrow significantly more of their endowment. High-score subjects do the same for only the 15 week delay.

Table 2 about here

Finally, we note that there are only small and statistically insignificant differences between the early payment choices of high- and lower-Baccalauréat-score participants in our overall sample which combines all treatments. Specifically, lower-score participants select a slightly higher overall level of early payment, and display slightly more present bias (which may be taken as a proxy of impulsivity), but neither gap is significant at conventional levels. ${ }^{21}$ As the next section shows, however, this aggregate result obscures sizeable differences in the effects of treatment on the behavior of high- versus lower-score participants.

\subsection{Simple Estimates of Treatment Effects}

Our first look at the effects of the various treatments is non-parametric. Figure 3 presents the mean demand for early payments across the Baseline, Depletion, Placebo and Sugar treatments by

\footnotetext{
${ }^{20} \mathrm{~A}$ regression approach is necessary because price ratios are not exactly balanced across the $t$ dimension.

${ }^{21}$ Averaged across all choices, lower-score participants allocate about $€ 0.70$ more experimental income $($ S.E. $=0.54$, clustered by individual) to the earlier payment date than high-score participants. This difference is not significant. We add interaction terms between the dummy variables for $t=5$ and $t=15$ and high-score as well as a high-score level effect into the present bias regressions from Table 2. The gap between early demand when $t=0$ versus $t=5$ is about $€ 0.31$ smaller for high-score participants, but this difference is not significant $(\mathrm{S}$.E. $=0.38)$. The signs and significances of the non-interacted dummies are unaffected.
} 
Baccalauréat score. Since these comparisons are between individuals, the treatments are balanced with respect to prices, delays and start dates.

Figure 3 about here

Result 3 - For the lower test score sample, depletion, a sugared drink and a non-sugared drink all reduce the demand for early payment. All of these treatment effects are absent among participants with very high test scores.

The $p$-values in Figure 3 indicate that all three treatments reduce demand for early income amongst lower-score participants, with particularly strong sugar effects $(p=0.003)$ and depletion effects $(p=0.046)$. The placebo effect is significant $(p=0.093)$, but is almost half the magnitude of the sugar effect; the difference between the two effects is significant $(p=0.056)$, indicating that the sugar treatment had effects on choice above and beyond that of the placebo. ${ }^{22}$ On the other hand, only the sugar treatment affects the demand for early income significantly (and positively) of the high-score subjects $(p=0.082)$. This effect is not significantly different from the placebo effect at conventional levels $(p=0.143)$ however.

A final noteworthy finding in Figure 3 is that high- and lower-score subjects differ substantially in their Baseline choices. The difference of $€ 3.07$ between the groups' early payment demand in the Baseline is significant $(p=0.011)$. Recalling that there was no significant difference between high- and lower-score participants overall, this suggests that, in essence, our three interventions have the effect of narrowing the behavioral difference between high- and lower-score participants by reducing lower-scoring participants' demand for early income. The next result probes the sources of this difference-reducing effect further.

Result 4 - The negative effect of all three treatments on lower-score participants' demand for early payment is strongest in cases where the price of early income is high.

\footnotetext{
${ }^{22}$ We use participants' estimates of the calories their beverage contained in order to ascertain whether this difference is due to psychology or physiology. Amongst lower-score subjects, there is no evidence that the magnitude of the Sugar-Placebo gap is affected by the beliefs about the drink or that beliefs themselves generate differences in demand.
} 
Figures A2 and A3 in Appendix plot the demand curves for early payments for each $(t, k)$ pair for lower-score and high-score participants, respectively. The lower-score participants exhibit a similar level of demand across all treatments at low price levels. As the price of early income rises, early payments decline more rapidly in the Depletion, Sugar, and Placebo treatments than in the Baseline. The high-score participants show a similar level of demand to the lower-score participants at low prices, but demand is highly price-sensitive in all four treatments. In this sense, the treatments appear to make the lower-score participants more price-sensitive, and thus more similar to the high-score participants' behavior.

To determine the statistical significance of the above effects, we define three price levels based on the relative value of early tokens. When early tokens are worth $€ 0.90$ or more we say the price is low, when they are worth between $€ 0.80$ and $€ 0.90$, we say the price is medium and when they are worth $€ 0.80$ or less, we say the price is high. ${ }^{23}$ Table 3 presents OLS regressions of early payment demand on the treatment dummy variables split by price level. At medium and high prices all three treatments have significant effects for the lower-score group and the magnitude of the sugar effect is larger at high as opposed to low prices. The sugar effect is significantly greater than the placebo effect in the medium price condition $(p=0.003)$ and borderline significantly greater in the high price condition $(p=0.105)$. Column (3) suggests an elasticity-reducing effect of the Sugar treatment on the high-score subjects, but the effects are not statistically different from the Placebo effects in either medium or high price condition ( $p=0.132$ and $p=0.218$ respectively).

Table 3 about here

In sum, our nonparametric analysis shows that all three treatments (Depletion, Placebo and Sugar) reduce early demand among subjects with lower Baccalauréat test scores, who are more representative of the educated French population than our high-test score sample. This apparent increase in 'patience' occurs only when the price of early income is high, so the treatments effectively make lower-score subjects more price-sensitive and therefore their overall behavior more similar to our 'elite' sample.

\footnotetext{
${ }^{23}$ Note that this definition focuses on the most salient aspect of the price presented to the participants: the changing value of an early token within a particular choice screen ( $t, k$ combination). Thus, the ranking is different than one based on annualized interest rate.
} 


\subsection{Treatment Effects in a Structural Model of Time Preferences}

To measure whether the treatments affected different aspects of participants' preferences, ${ }^{24}$ we now estimate a simple structural model of intertemporal preferences in which the treatments can affect each one of the fundamental utility parameters (specifically, their discount rate, present bias and intertemporal substitution parameters). One primary advantage of the CTB method is that it allows for the precise estimation of the parameters of structural models of intertemporal choice, even on the individual level. We will consider two types of structural treatment effects: aggregate and individual. Aggregate effects will compare one treatment-specific parameter estimate to another and individual effects will compare the set of individual-specific parameter estimates within one treatment to those from another. The two approaches yield similar results. As in section 4.2, splitting the sample by test score is essential for understanding the treatment effects.

We first provide a characterization of an individual's decision problem. Consider individual $i$ making decision $j$. Continue to denote $X$ as the number of tokens received at the earlier date and $Y$ the number at the later date. Individual $i$ is assumed to have power income utility (with exponent $\alpha$ ) that is additively separable across time periods in a $\beta-\delta$ form (Laibson 1997; O'Donoghue and Rabin 1999). Choice $j$ is characterized by the price of sooner income, $R$, a delay between the two payment dates, $k$, and an indicator for whether or not the sooner date is today, $T$ (equal to 1 if $t$ $=0$, and 0 otherwise). As in equation (1), $M$ is the total number of tokens available. We suppose that subjects optimize in the following way: 25

$$
\left(X_{i j}, Y_{i j}\right)=\underset{X, Y}{\arg \max } \quad X^{\alpha}+\beta^{T_{j}} \delta^{k_{j}} Y^{\alpha} \quad \text { subject to } \quad R_{j} X+Y \leq M .
$$

To identify preferences, we follow the approach of AS by applying non-linear least squares (NLS) to the demand function for sooner tokens, derived directly from equation 2. This approach

\footnotetext{
${ }^{24}$ For example, while reduced utility curvature (higher $\alpha$ ) is associated with higher price-sensitivity, it should also increase the response to $k$ (the gap between the payment dates). In general, because the demand functions implied by most theoretically interesting demand functions are nonlinear, the predicted marginal effects of each parameter depend on the levels of all the others, making simple regression tests only roughly informative about the effects of treatments on preference parameters.

${ }^{25}$ Note that equation (1) implies that the set of available allocations is convex: that the tokens can be infinitely divided. While we offer subjects 17 possible allocations along the budget frontier rather than an infinite number, we argue that this is a suitable approximation to convexity. Andreoni, Kuhn and Sprenger (2013) perform a similar exercise with 6 allocations and find no evidence of bias due to discretization.
} 
yields the structural regression equation

$$
X_{i j}=\frac{M\left(\beta_{j}^{T} \delta_{j}^{k} R_{j}\right)^{\frac{1}{\alpha-1}}}{1+R_{j}\left(\beta_{j}^{T} \delta_{j}^{k} R_{j}\right)^{\frac{1}{\alpha 0-1}}}+\epsilon_{i j}
$$

To analyze and test treatment effects, we replace $\alpha$ with

$$
\alpha_{1}+\alpha_{2} D_{i}+\alpha_{3} P_{i}+\alpha_{4} S_{i}
$$

where $D, P$ and $S$ are treatment indicator variables, and make similar substitutions for $\beta$ and $\delta$. Instead of presenting results on $\delta$ itself, we use $r=\delta^{-365}-1$, the yearly discount rate equivalent, for ease of interpretation.

Setting out the structural form in (2)-(4) allows us to be more precise about how our manipulations of the cognitive and physiological environments affect subjects' intertemporal choices than the more generic notions of 'impatience' or 'impulsivity'. For example, if a treatment raises $r$, it should increase subjects' demand for early rewards relative to late rewards regardless of the amount of delay between the two payment dates, and regardless of whether the early period corresponds to the date of the experiment or a future date. If a treatment lowers $\beta$ (the present bias parameter) below 1, it increases subjects' attraction only to rewards that are received on the date of the experiment; high levels of present bias (low values of $\beta$ ) generate temporal inconsistencies in choices that may correspond to psychological notions of a failure of willpower (i.e. a greater impulsiveness). Finally, if treatments increase $\alpha$, they make subjects more responsive to the costs of early income, which under some conditions (i.e. access to capital markets) might also be interpreted as an 'improvement' in the effectiveness of subjects' decisions. All three notions are conflated in the more amorphous notion of willpower that is often used to interpret experimental results on the effects of willpower depletion.

We first estimated equation (3) without treatment effects, following our modification of the CTB technique introduced by AS in the calibration of prices. Our estimate of the aggregate yearly discount rate is $21.8 \%$ for lower-score types $($ S.E. $=5.9 \%$ ) and $21.0 \%$ for high-score types (S.E. $=4.1 \%) .{ }^{26}$ Our estimates of the $\beta$ parameter are $0.976($ S.E. $=0.008)$ for lower-score and 0.988

\footnotetext{
${ }^{26}$ The corresponding specification from AS (Table 2, column (3)) estimates a rate of $37.7 \%$ with a standard error of $8.7 \%$. Because our max time horizon is slightly longer, we would expect a slightly lower estimate of the rate if
} 
$($ S.E. $=0.007)$ for high-score, with both values significantly less than 1 ( $p=0.005$ and $p=0.086$, respectively). Thus, in contrast to AS who estimate $\beta=1.007$ (S.E. $=0.006$ ), we find evidence of present bias in the $\beta-\delta$ form. ${ }^{27}$ Lastly, we estimate a lower degree of curvature: $\alpha=0.922$ (S.E. $=0.008)$ for lower-score and $0.942($ S.E. $=0.005)$ for high-score individuals as opposed to 0.897 $($ S.E. $=0.009)$ in AS.

Result 5 - The treatment effects on the structural parameters are concentrated on $\alpha$, the utility function curvature parameter. The magnitudes are economically significant at interest rates that correspond to predatory credit instruments.

Table 4 presents estimates of treatment effects on the parameters of a common utility function, shared by all individuals in each estimation sample. The treatment effects only show up as significant for utility curvature. Both Drink treatments significantly decrease lower-score curvature, but the effect is significantly larger for the sugared drink $(p=0.020)$. While the high-score curvature increase is significant only for the Sugar treatment, this effect is not significantly different from the effect of the Placebo treatment $(p=0.167)$. In contrast to the simple estimates of treatment effects, we do not see a significant effect of the Depletion treatment on the three utility parameters, taken individually, amongst the lower-score group. However, depletion effects on both the present bias and the curvature parameters have $p$-values below 0.15 and the joint hypothesis that these effects are zero is rejected $(p=0.088)$. The two Drink treatments have significant joint effects as well. All three effects on parameters are jointly different from zero in the Placebo treatment $(p=0.021)$ and in the Sugar treatment $(p=0.001)$ in the lower-score sample. The Sugar treatment also has a significant effect on all three parameters in the opposite direction in the high-score sample $(p=$ $0.033)$.

Table 4 about here

The fact that the treatment effects operate through utility curvature is consistent with Result 4: they make the lower-score individuals more price sensitive. In the limiting case where the utility individuals display some insensitivity to the exactness of dates far in the future.

${ }^{27}$ While this magnitude of present bias over pure allocations of money is not economically meaningful in our experiment, a $3 \%$ distortion of preferences could be very important for major financial decisions. 
function has no curvature, optimal choices move from one corner to the other as prices change. The less curvature the function has, the closer we are to this case, and the more responsive individuals will be. To illustrate this, consider subjects from our experiment making a decision about taking a 2-week payday loan against a $€ 1000$ paycheck that comes with a $15 \%$ charge (APR $=390 \%)$. Roughly, the optimal loan for a lower-score, Baseline treatment individual is $€ 310$, which results in a $€ 60$ charge. Holding the discount and present-bias factors constant ${ }^{28}$ and switching to the Depletion curvature estimate reduces the loan to $€ 220$ (charge of $€ 40$ ), the Placebo curvature estimate to $€ 140$ (charge of $€ 20$ ) and the Sugar curvature estimate to $€ 60$ (charge of $€ 10$ ).

Turning now to our method that allows each subject to have his/her own set of utility parameters, $(\alpha, \beta$ and $\delta)$, we make a couple of adaptations that are dictated by the estimation results. First, we drop 21 individuals who lack enough choice variation for the successful estimation of the parameters. Second, because using the NLS technique with only 45 observations per subject delivers some extreme outlying estimates, we trim the sample at the 5th and 95th percentiles of the distribution of all three parameter estimates. This excludes 24 more subjects, leaving a sample of 104. Of the 45 excluded subjects, 28 are from the lower-score sample and 17 are from the high-score sample.

Table 5 reports estimates of treatment effects on the individual-specific parameters using quantile regressions at the median value of the estimate distribution. Specifically, for each of the three parameters, we estimated a median regression on 104 observations in which the participant's parameter estimate was the dependent variable and the three treatment indicators were the only regressors. Standard errors for these estimates are obtained via bootstrap with 1000 replications. The estimated individual effects are largely consistent with the aggregate effects. Both drinks significantly decrease curvature in the lower-score sample. The depletion effect on curvature in the lower-score sample is now marginally significant; whereas it was marginally insignificant in the aggregate test. The Depletion and Sugar treatments appear to have minor present-bias inducing effects for the high-score group.

Table 5 about here

\footnotetext{
${ }^{28}$ We do this to recognize that the effects we find on $r$ and $\beta$ are not estimated precisely. If we do take these effects into account however, the gap between Baseline and the other treatments is larger. While the optimal loan remains at $€ 310$ in Baseline, it is $€ 160$ in Depletion, $€ 90$ in Placebo and $€ 30$ in Sugar.
} 
All three treatments increase the amount of deferred income for the lower-score individuals by reducing utility curvature such that budgets featuring above-market interest rates generate large differences in allocations versus the Baseline. There exists some evidence that the Sugar treatment had stronger effects than the Placebo treatment.

\subsection{Robustness}

If time preferences are indeed dependent to a degree on physiological conditions, it would be encouraging if our treatment effects were moderated by the condition in which individual subjects entered the lab. While subjects were asked not to eat or drink for at least three hours prior to the experiment, our survey indicated that there was substantial variation in the degree of adherence to this request. Almost $19 \%$ of individuals report they had not eaten since the day before the experiment and around $7 \%$ had eaten within the three hour window prior to the experiment. We expect that subjects should have been more susceptible to the interventions the longer they went without eating. Table 6 presents treatment effect regressions on demand for early payment with interactions between the Depletion, Placebo and Sugar variables with the number of hours since last meal.

Consistent with our baseline results, we find no significant treatment effects on the high-scoring subjects; this group's decisions are also unaffected by the amount of elapsed time since their last meal. Lower-scoring subjects, on the other hand, become less patient as the time since their last meal increases; this behavior is consistent with Briers et al.'s (2006) and Danziger et al.'s (2011) evidence. ${ }^{29}$ Also, as predicted, lower-scoring subjects' sensitivity to all three of our interventions increases with elapsed time since their last meal. ${ }^{30}$ While this may not be surprising for the drink treatments, it is perhaps noteworthy that "depleting" our subjects via the Stroop test also has a larger patience-enhancing effect on hungry than on recently-nourished subjects. This finding reinforces our suggestion that engaging in a novel but cognitively demanding task can actually (at

\footnotetext{
${ }^{29}$ Briers et al. found that the desire for caloric resources increases the desire for money. Looking at decisions made by an Israeli parole board, Danziger et al. found that parole was much more likely to be granted early in the day than later in the day, conditional on crime, sentence and ethnicity. Since a judge's reputation is harmed more by inappropriately granting, as opposed to inappropriately refusing parole, fatigued judges 'take the easy way out' relative to rested judges. Following the board's midmorning snack, there was a substantial spike in the percentage of prisoners who were granted parole.

${ }^{30}$ Note that the uninteracted treatment effects no longer enter as significant because they are estimates specific to the intercept where the time since last meal is zero.
} 
least temporarily) improve a vulnerable subject's ability to focus on economic decisions.

Table 6 about here

To rule out mood or affect as potential drivers of our sugar or placebo effects, we use the elicited mood and beverage enjoyment data from the post-drink surveys (Drink treatments) and entry surveys (Baseline treatment). ${ }^{31}$ First and foremost, mood is not predictive of demand in our experiment. Second, we use a specification identical to our hours-since-last-meal analysis, but replace that variable with the self-reported mood variable, and exclude individuals from the Depletion treatment (since their mood elicitation took place prior to the Stroop task). Results are in Appendix Tables A2 and A3. We again find no substantive evidence that mood is related to demand for lower-score participants, ${ }^{32}$ and weak evidence that high-score participants in the placebo condition may demand smaller early payments as their mood improves. ${ }^{33}$

To add credence to our use of the Baccalauréat exam score as a measure of cognitive ability, we present treatment effect estimates split by CRT performance instead of by Baccalauréat score. ${ }^{34}$ As noted, these estimates should be interpreted with caution since the treatments may have affected the subjects' CRT performance, just as they affected the subjects' performance in the time-preference task. That said, consistent with our results using the Baccalauréat, we find significant effects of the treatments on time preferences only for those who failed to answer a single CRT question correctly (slightly more than $70 \%$ of these individuals are in the lower-score group). Results are presented in Table 7.

\section{Table 7 about here}

Finally, we note that while our structural demand equation (3) is for a continuous measure of early income, our experimental subjects could choose only integer numbers of tokens; relatedly, optimal choices in (3) approach corner solutions as the degree of preference curvature approaches zero ( $\alpha$ approaches one). ${ }^{35}$ To check whether this affects our estimates, we estimated specifications

\footnotetext{
${ }^{31}$ Both mood and beverage enjoyment are elicited as numbers from 1 (negative) to 10 (positive).

${ }^{32}$ The same is true of elicited beverage enjoyment.

${ }^{33}$ Attempts to replicate the Ifcher and Zarghamee (2011) result by using our treatment variables as instruments suffer from a lack of relevance: our treatments do not appear to affect mood.

${ }^{34}$ As mentioned earlier, CRT and Baccalauréat performance are positively and significantly correlated.

${ }^{35}$ In fact, around $75 \%$ of choices in our experiment are at corners, reflecting the relatively low degree of estimated preference curvature among our subjects, especially at high cognitive ability levels and in the presence of interventions that reduce curvature.
} 
with three options: 1) sooner corner, 2) interior and 3) later corner using a multinomial logit specification. Results are found in Appendix Table A4. Reassuringly, in the lower-score sample, the probability of choosing the sooner corner is significantly lower in the Depletion and Sugar treatments and the probability of choosing the later corner is significantly greater in the Depletion, Sugar and Placebo treatments.

\section{Discussion and Conclusion}

This paper studies the effects of experimental manipulations of prior impulse-controlling activity and sugar consumption on time preferences. A key innovation of our approach is an explicit model of intertemporal choice which allows us to distinguish three conceptually distinct aspects of 'patience' (the tendency to defer income) that might be affected by the cognitive and physiological environment: discount rates, present bias, and price sensitivity. We find that intertemporal choices are sensitive to transient features of the choice environment, but not necessarily in ways that are consistent with a willpower-based model. Instead, exposure to the Stroop (1935) task prior to the elicitation of time preferences makes lower-test-score participants more responsive to high prices for early income. It is 'as if' the Stroop test primed the subjects to think more carefully about their subsequent economic decisions. Our interpretation of this Depletion results is that the 'attention/focusing' effect of engaging in the Stroop task outweighs any effects of willpower depletion on the subsequent time preference elicitation procudure. This interpretation is consistent with Benartzi and Thaler's (2001) and Beshears et al.'s $(2011,2013)$ evidence that simplifying the choice environment improves financial decisions. ${ }^{36}$

In our Drink treatments, we find that drinking either the placebo beverage or the sugared beverage ten minutes prior to the time preference task also increases patience, and-like the Stroop taskdoes so by raising subjects' sensitivity to high prices. The magnitude of the sugar effect is significantly greater than the magnitude of the placebo effect, consistent with a role for blood glucose in sustaining willpower. However, the finding that the placebo beverage has a level effect over the

\footnotetext{
${ }^{36}$ Our depletion result is also consistent with Tuk, Trampe and Warlop (2011)'s recent finding that increased urination urgency associated with a full bladder improves subjects' ability to resist more immediate temptations in monetary decision making, and with Benjamin, Brown and Shapiro's (2013) evidence that interfering with individuals' ability to focus induces small-stakes risk aversion.
} 
baseline raises questions about the role of blood glucose per se. Indeed, recent findings by Molden et al. (2012) and Sanders et al. (2012) show that simply rinsing one's mouth with a sugared beverage without swallowing (with no effect on blood glucose) bolsters impulse control in similar ways to ingesting sugar; related neurological evidence indicates that the sensing of the carbohydrate in the mouth activates a part of the brain that is highly sensitive to incentives (Kringelbach 2004; Chambers, Bridge and Jones 2009). Since our placebo drink did contain a very small amount of sugar -though not enough to affect blood glucose levels- this mechanism could account for our findings.

An alternative explanation of our estimated Drink effects is a substitution between primary and secondary rewards. Indeed, the drink - whether sugared or not- could be perceived as a reward, since participants were asked not to eat or drink for three hours prior to the experiment. Consistent with the notion of a common neural value of rewards (see Dreher 2009), receiving a drink as a reward may reduce participants' desire for an immediate secondary reward (i.e. money on the day of the experiment). Or, in line with Briers et al. (2006), it may decrease the desire for immediate financial resources. One difficulty with this hypothesis, however, is that the drinks should act primarily on subjects' present bias, not on their price-sensitivity as we observe; the drinks should also affect both lower- and higher-score subjects, which is not what we observe. ${ }^{37}$

Finally, a more 'economic' mechanism that could explain our results relates to a critique of time-preference elicitation experiments (Chabris, Laibson and Schuldt 2008), namely that the choices of agents with access to capital markets and awareness of the rates they face in such markets should be more informative about their capital market options than their subjective preference parameters. Specifically, in our convex environment these agents should pick corner solutions that depend on whether the gross interest rate on a particular choice is above or below their outside rate option. While our Drink and Depletion treatments cannot, of course, affect our participants' capital market options, it is possible that they affected the extent to which participants had the mental energy or focus to incorporate those options into their decisions. Such increased sensitivity to outside rates would make our estimated indifference curves less convex (linear in the extreme),

\footnotetext{
${ }^{37}$ Alternatively, the drinks could satisfy a different biological need than the need for energy (i.e. quenching thirst). Relieving subjects' thirst may improve their ability to concentrate on the time choice task compared with the Baseline treatment. Unlike the reward substitution hypothesis, this mechanism seems more consistent with the fact that the treatments operate via price-sensitivity rather than present bias or discount rates.
} 
and thus be reflected in our estimates of $\alpha$. Carvalho, Prina and Sydnor (2013) study the effects of randomly providing individuals with a savings account on time preferences. Echoing our results, their treatment effects are concentrated on utility curvature: subjects with new accounts exhibit more linear preferences, suggesting increased sensitivity of choices to market options.

An additional feature of our estimated treatment effects is that they are large in magnitude. We estimate that lower-score subjects in our Baseline treatment would demand an advance of $€ 310$ when offered a 2 -week payday loan that comes with a $15 \%$ charge $(A P R=390 \%)$, for a total loan charge of $€ 60$. Our Depletion treatment reduces the desired loan to $€ 220$ (charge of $€ 40$ ). The Placebo treatment further reduces loan demand to $€ 140$ (charge of $€ 20$ ) and the Sugar treatment to $€ 60$ (charge of $€ 10$ ). ${ }^{38}$ Payday loans such as the above are considered by many to be 'predatory' in that their short-term nature takes advantage of scope insensitivity in interest rates to charge astronomical rates. In these situations, our finding that all of the treatment effects operate through the intertemporal elasticity of substitution indicates that unless consumers are highly attuned to their task at hand, they may ignore substantial price differences across assets or credit payments. ${ }^{39}$ This emphasizes the need to both help consumers make active and aware choices whenever possible and be vigilant in preventing firms from purposefully taking advantage of compromising cognitive environments.

As noted, all the above treatment effects are largely absent among subjects with very high cognitive abilities (corresponding to the top decile of French high school graduates). That said, our main results pertain to a subject pool whose cognitive ability is still well above the national mean (representing about the 50th-90th percentiles of high school graduates). This suggests that sensitivity of economic choices to transitory environmental features like those studied in this paper is likely widespread in most populations of interest.

\section{References}

[1] J. Andreoni, M.A. Kuhn, and C. Sprenger. On measuring time preferences. Working paper, UC San Diego, 2013.

\footnotetext{
${ }^{38}$ Using changes to $\alpha$ only.

${ }^{39}$ For those concerned about the external validity of our experimental measures, we point to existing literature that demonstrates a strong relationship between experimentally elicited impatience and wealth and health investment (Hastings and Mitchell, 2011), present-bias and credit card debt (Meier and Sprenger, 2010) and time discounting and credit scores (Meier and Sprenger, 2012).
} 
[2] J. Andreoni and C. Sprenger. Estimating time preferences from convex budgets. American Economic Review, 102(7):3333-3356, 2012.

[3] N. Augenblick, M. Niederle, and C. Sprenger. Working over time: Dynamic inconsistency in real effort tasks. Working paper, NBER No. 18734, 2013.

[4] R.F. Baumeister, E. Bratslavsky, M. Muraven, and D.M. Tice. Self-control depletion: Is the active self a limited resource? Journal of Personality and Social Psychology, 74(5):1252$1265,1998$.

[5] S. Benartzi and R.H. Thaler. Naïve diversification strategies in defined contribution plans. American Economic Review, 91(1):79-98, 2001.

[6] D.J. Benjamin, S.A. Brown, and J.M. Shapiro. Who is "behavioral"? cognitive ability and anomalous preferences. Journal of the European Economic Association, 2013. Forthcoming.

[7] B.D. Bernheim and A. Rangel. Addiction and cue-triggered decision processes. American Economic Review, 94(5):1558-1590, 2004.

[8] J. Beshears, J.J. Choi, D. Laibson, and B.C. Madrian. How does simplified disclosure affect individuals' mutual fund choices? In D.A. Wise, editor, Exploration in the Economics of Aging. University of Chicago Press, 2011.

[9] J. Beshears, J.J. Choi, D. Laibson, and B.C. Madrian. Simplification and saving. Journal of Economic Behavior and Organization, 2013. Forthcoming.

[10] B. Briers, M. Pandelare, S. Dewitte, and L. Warlop. A dual-self model of impulse control. American Economic Review, 96(5):1449-1476, 2006.

[11] B. Briers, M. Pandelare, S. Dewitte, and L. Warlop. Hungry for money: The desire for caloric resources rsources increases the desire for financial resource and vice-versa. Psychological Science, 17(11):939-943, 2006.

[12] A. Bucciol, D. Houser, and M. Piovesan. Temptation and productivity. Journal of Economic Behavior and Organization, 78(1):126-136, 2011.

[13] N. Burger, G. Charness, and J. Lynham. Field and online experiments on self-control. Journal of Economic Behavior and Organization, 77(3):393-404, 2011.

[14] M. Callen, M. Isaqzadeh, J.D. Long, and C. Sprenger. Violence and risk preference: Experimental evidence from afghanistan. American Economic Review, 2013. Forthcoming.

[15] G.D. Carroll, J.J. Choi, D. Laibson, B.C. Madrian, and A. Metrick. Optimal defaults and active choices. Quarterly Journal of Economics, 124(4):1639-1674, 2009.

[16] L. Carvalho, S. Prina, and J. Sydnor. The effects of savings on risk-taking and intertemporal choice behavior: Evidence from a randomized experiment. Working paper, 2013.

[17] C.F. Chabris, D. Laibson, and J.P. Schuldt. Intertemporal choice. In S. Durlauf and L. Blume, editors, New Palgrave Dictionary of Economics. Palgrave Macmillan, 2008. 
[18] E.S. Chambers, M.W. Bridge, and D.A. Jones. Carbohydrate sensing in the human mouth: Effects on exercise performance and brain activity. Journal of Physiology, 587(8):1779-1794, 2009.

[19] S. Danziger, J. Levav, and L. Avanaim-Pesso. Extraneous factors in judicial decisions. Proceedings of the National Academy of Sciences, 108(17):6889-6892, 2011.

[20] C.N. DeWall, R.F. Baumeister, T.F. Stillman, and M.T. Gailliot. Violence restrained: Effects of self-regulation and its depletion on aggression. Experimental Social Psychology, 43(1):6276, 2007.

[21] D.L. Dickinson and T. McElroy. Rationality around the clock: Sleep and time-of-day effect on guessing game responses. Economics Letters, 108(2):245-248, 2010.

[22] T. Dohmen, A. Falk, D. Huffman, and U. Sunde. Are risk aversion and impatience related to cognitive ability? American Economic Review, 100(3):1238-1260, 2010.

[23] R.T. Donohoe and D. Benton. Blood glucose control and aggressiveness in females. Personality and Individual Differences, 26(5):905-911, 1999.

[24] D. Dotter. Breakfast at the desk: The impact of universal classroom breakfast programs on academic performance. Working paper, UC San Diego, 2013.

[25] J.C. Dreher. Decomposing brain signals involved in value-based decision-making. In J.C. Dreher and L. Tremblay, editors, Handbook of Reward and Decision Making. Burlington: Academic Press, 2009. 137-163.

[26] S. Frederick. Cognitive reflection and decision making. Journal of Economic Perspectives, 19(4):25-42, 2005.

[27] D.C. Funder and J. Block. The role of ego-control, ego-resiliency, and iq in delay of gratification in adolescence. Journal of Personality of Social Psychology, 57(6):1041-1050, 1989.

[28] M.T. Gailliot and R.F. Baumeister. The physiology of willpower: Linking blood glucose and self-control. Personality and Social Psychology Review, 11(4):303-327, 2007.

[29] M.T. Gailliot, R.F. Baumeister, C.N. DeWall, J.K Maner, E.A. Plant, D.M. Tice, L.E. Brewer, and B.J. Schmeichel. Self-control relies on glucose as a limited energy source: Willpower is more than a metaphor. Journal of Personality and Social Psychology, 92(2):325-336, 2007.

[30] M.T. Gailliot, B.M. Peruche, E.A. Plant, and R.F. Baumeister. Stereotypes and prejudice in the blood: Sucrose drinks reduce prejudice and stereotyping. Journal of Experimental Social Psychology, 45(1):288-290, 2009.

[31] E.H. Gordijn, I. Hindriks, W. Koomen, A. Dijksterhuis, and A. Van Knippenberg. Consequences of stereotype suppression and internal suppression motivation: A self-regulation approach. Personality and Social Psychology Bulletin, 30(2):212-224, 2004.

[32] B. Greiner. An online recruitment system for economic experiments. Forschung und wissenschaftliches Rechnen, 63:79-93, 2004. 
[33] J.S. Hastings and O.S. Mitchell. How financial literacy and impatience shape retirement wealth and investment behaviors. Working paper, NBER No. 16740, 2011.

[34] J.M. Hinson, T.J. Jameson, and P. Whitney. Impulsive decision making and working memory. Journal of Experimental Psychology: Learning, Memory, and Cognition, 29(2):298-306, 2003.

[35] J. Ifcher and H. Zarghamee. Happiness and time preference: The effect of positive affect in a random-assignment experiment. American Economic Review, 101(7):3109-3129, 2011.

[36] D. Kahan, J. Polivy, and C.P. Herman. Conformity and dietary disinhibition: A test of the ego-strength model of self-regulation. International Journal of Eating Disorders, 32(2):165$171,2003$.

[37] C. Kirby, G. Winston, and M. Santiesteban. Impatience and grades: Delay-discount rates correlate negatively with college gpa. Learning and Individual Differences, 15(3):213-222, 2005.

[38] B. Koszegi and A. Szeidl. A model of focusing in economic choice. Quarterly Journal of Economics, 128(1):53-104, 2013.

[39] M.L. Kringelbach. Food for thought: Hedonic experience beyond homeostasis in the human brain. Neuroscience, 126(4):807-819, 2004.

[40] D. Laibson. Golden eggs and hyperbolic discounting. Quarterly Journal of Economics, 112(2):443-477, 1997.

[41] C.M. MacLeod. Half a century of research on the stroop effect: An integrative review. Psychological Bulletin, 109(2):163-203, 1991.

[42] N.L. Mead, R.F. Baumeister, F. Gino, M.E. Schweitzer, and D. Ariely. Too tired to tell the truth: Self-control resource depletion and dishonesty. Journal of Experimental Social Psychology, 45(3):594-597, 2009.

[43] S. Meier and C. Sprenger. Present-biased preferences and credit card borrowing. American Economic Journal: Applied Economics, 2(1):193-210, 2010.

[44] S. Meier and C. Sprenger. Time discounting predicts creditworthiness. Psychological Science, 23(1):56-58, 2012.

[45] W. Mischel, E.B. Ebbesen, and A. Raskoff Zeiss. Cognitive and attentional mechanisms in delay of gratification. Journal of Personality and Social Psychology, 21(2):204-218, 1972.

[46] D.C. Molden, C.M. Hui, A.A. Scholer, B.P. Meier, E.E. Noreen, P.R. D’Agostino, and V. Martin. Motivational versus metabolic effects of carbohydrates on self-control. Psychological Science, 23(10):1137-1144, 2012.

[47] M. Muraven, R.L. Collins, and K. Neinhaus. Self-control and alcohol restraint: An initial application of the self-control strength model. Psychology of Addictive Behaviors, 16(12):113120, 2002. 
[48] M.R. Muraven and R.F. Baumeister. Self-regulation and depletion of limited resources: Does self-control resemble a muscle? Psychological Bulletin, 126(2):247-259, 2000.

[49] M.R. Muraven, R.L. Collins, S. Shiffman, and J.A. Paty. Daily fluctuations in self-control demands and alcohol intake. Psychology of Addictive Behaviors, 19(2):140-147, 2005.

[50] T. O'Donoghue and M. Rabin. Doing it now or later. American Economic Review, 89(1):103$124,1999$.

[51] E. Ozdenoren, S.W. Salant, and D. Silverman. Willpower and the optimal control of visceral urges. Journal of the European Economic Association, 10(2):342-368, 2012.

[52] J.A. Richeson and J.N. Shelton. When prejudice does not pay: Effects of interracial contact on executive function. Psychological Science, 14(3):287-290, 2003.

[53] J.A. Richeson and S. Trawalter. Why do interracial interactions impair executive function? a resource depletion account. Journal of Personality and Social Psychology, 88(6):934-947, 2005.

[54] J.A. Richeson, S. Trawalter, and J.N. Shelton. African americans' implicit racial attitudes and the depletion of executive function after interracial interactions. Social Cognition, 23(4):336$352,2005$.

[55] A. Rustichini, C. DeYoung, J. Anderson, and S.V. Burks. Toward the integration of personality theory and decision theory in the explanation of economic and health behavior. IZA Discussion Paper 6750, 2012.

[56] M.A. Sanders, S.D. Shirk, C.J. Burgin, and L.L. Martin. The gargle effect: Rinsing the mouth with glucose enhances self control. Psychological Science, 23(12):1470-1472, 2012.

[57] N.A. Shamosh and J.R. Gray. Delay discounting and intelligence: A meta-analysis. Intelligence, 36(4):289-305, 2008.

[58] H.M. Shefrin and R.H. Thaler. The behavioral life-cycle hypothesis. Economic Inquiry, 26(4):609-643, 1988.

[59] Y. Shoda, W. Mischel, and P.K. Peake. Predicting adolescent cognitive and self-regulatory competencies from preschool delay of gratification: Identifying diagnostic conditions. Developmental Psychology, 26(6), 1990.

[60] D.W. Stephens and R.K. John. Foraging Theory. Princeton University Press, Princeton, New Jersey, 1986.

[61] J.R. Stroop. Studies of interference in serial verbal reactions. Journal of Experimental Psychology, 18(6):643-662, 1935.

[62] T.S. Stucke and R.F. Baumeister. Ego depletion and aggressive behavior: Is the inhibition of aggression a limited resource? European Journal of Social Psychology, 36(1):1-13, 2006. 
[63] M.A. Tuk, D. Trampe, and L. Warlop. Inhibitory spillover: Increased urination urgency facilitates impulse control in unrelated domains. Psychological Science, 22(5):627-633, 2011.

[64] K.D. Vohs and T.F. Heatherton. Self-regulatory failure: A resource-depletion approach. Psychological Science, 11(3):249-254, 2000.

[65] X.T. Wand and R.D. Dvorak. Sweet future: Fluctuating blood glucose levels affect future discounting. Psychological Science, 21(2):183-188, 2010.

[66] K.A. Wesnes, C. Pincock, D. Richardson, G. Helm, and S. Hails. Breakfast reduces declines in attention and memory over the morning in schoolchildren. Appetite, 41(3):329-331, 2003. 
Table 1: Experimental Design

(1)

(2)

(3)

(4)

(5)

\begin{tabular}{|c|c|c|c|c|c|}
\hline Baseline & Entry survey & Rest & $\begin{array}{c}\text { Time preference } \\
\text { task }\end{array}$ & Stroop task & Exit survey \\
\hline Depletion & Entry survey & Rest & Stroop task & $\begin{array}{c}\text { Time preference } \\
\text { task }\end{array}$ & Exit survey \\
\hline Placebo & $\begin{array}{l}\text { Sugar-free drink \& } \\
\text { Entry survey }\end{array}$ & Rest & $\begin{array}{c}\text { Time preference } \\
\text { task }\end{array}$ & Stroop task & Exit survey \\
\hline Sugar & $\begin{array}{l}\text { Sugared drink \& } \\
\text { Entry survey }\end{array}$ & Rest & $\begin{array}{c}\text { Time preference } \\
\text { task }\end{array}$ & Stroop task & Exit survey \\
\hline
\end{tabular}

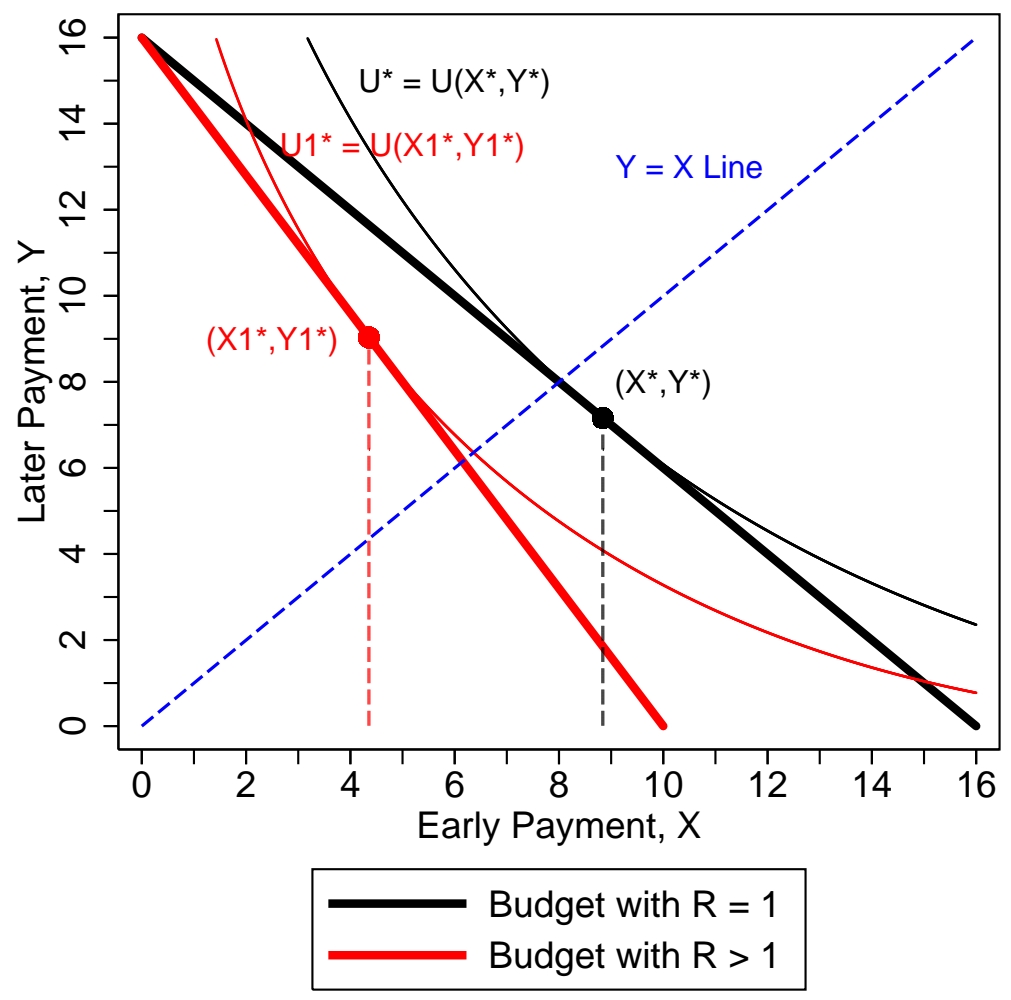

Figure 1: Predicted Behavior 


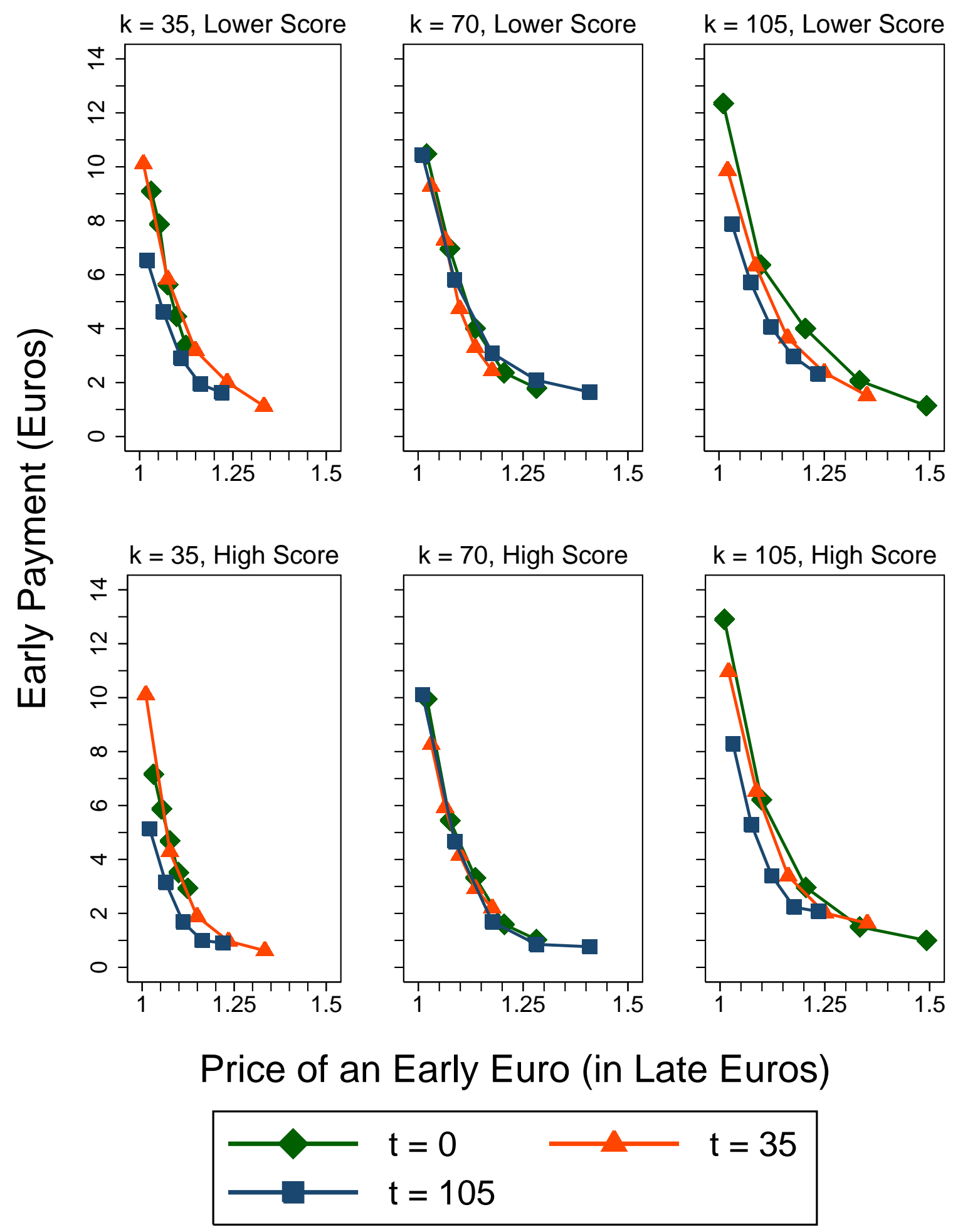

Figure 2: Demand Functions by Date of Early Payment, $t$, All Treatments 
Table 2: Effect of Start Date, $t$, on Early Payment Demand

\begin{tabular}{lccc} 
& \multicolumn{3}{c}{ Estimation Sample } \\
\hline & All Subjects & Lower-Score & High-Score \\
\hline Constant $(t=0, R=1)$ & $(1)$ & $(2)$ & $(3)$ \\
& $(0.437)$ & $(0.608)$ & $(0.627)$ \\
$1(t=5$ weeks $)$ & $-0.521^{* * *}$ & $-0.678^{* *}$ & -0.367 \\
& $(0.192)$ & $(0.264)$ & $(0.278)$ \\
$1(t=15$ weeks $)$ & $-1.324^{* * *}$ & $-1.308^{* * *}$ & $-1.340^{* * *}$ \\
& $(0.286)$ & $(0.409)$ & $(0.403)$ \\
Normalized Price Ratio $(R-1)$ & $-21.365^{* * *}$ & $-21.535^{* * *}$ & $-21.197^{* * *}$ \\
& $(1.197)$ & $(1.723)$ & $(1.675)$ \\
Clusters & & & \\
Observations & 149 & 74 & 75
\end{tabular}

${ }^{*} p<0.10,{ }^{* *} p<0.05,{ }^{* * *} p<0.01$

Standard Errors in parentheses, clustered by individual. 45 observations (budgets) per cluster. 


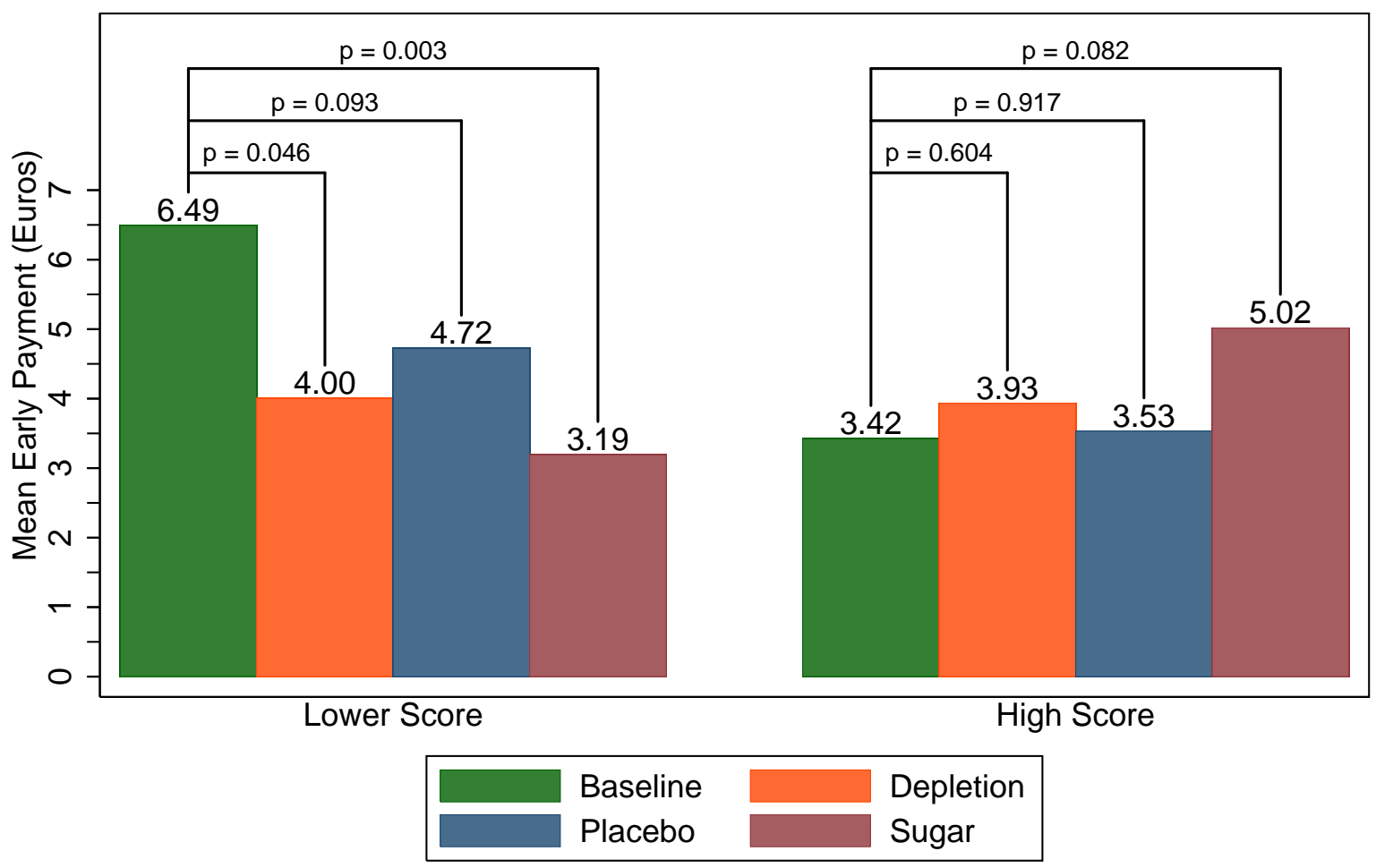

Figure 3: Mean Demand by Treatment

$p$-values are generated from regressions of the chosen early payment on treatment status with standard errors clustered at the individual level. The regression is run separately for lower- and high-score subjects. Each individuals makes 45 decisions, leaving us with a sample size of 3330 (74 clusters) in the lower-score group and 3365 (75 clusters) in the high-score group. An approach that collapses the data to individual-level means yields similar results. 
Table 3: Treatment Effect on Early Payment Demand by Price Level Estimation Sample

\begin{tabular}{|c|c|c|c|}
\hline & All Subjects & Lower-Score & High-Score \\
\hline & (1) & (2) & (3) \\
\hline Constant (Low price, Baseline) & $\begin{array}{c}7.976 \\
(0.803)\end{array}$ & $\begin{array}{c}8.809 \\
(1.036)\end{array}$ & $\begin{array}{c}6.449 \\
(1.146)\end{array}$ \\
\hline Low price X Depletion & $\begin{array}{c}-1.778 \\
(1.093)\end{array}$ & $\begin{array}{l}-2.585 \\
(1.590)\end{array}$ & $\begin{array}{l}-0.276 \\
(1.460)\end{array}$ \\
\hline Low price X Placebo & $\begin{array}{c}-0.865 \\
(1.074)\end{array}$ & $\begin{array}{c}-0.944 \\
(1.316)\end{array}$ & $\begin{array}{c}-0.492 \\
(1.703)\end{array}$ \\
\hline Low price X Sugar & $\begin{array}{c}-0.530 \\
(1.073)\end{array}$ & $\begin{array}{l}-2.569 \\
(1.567)\end{array}$ & $\begin{array}{c}1.444 \\
(1.433)\end{array}$ \\
\hline Medium price & $\begin{array}{c}-4.423^{* * *} \\
(0.534)\end{array}$ & $\begin{array}{c}-3.848^{* * *} \\
(0.645)\end{array}$ & $\begin{array}{c}-5.477^{* * *} \\
(0.876)\end{array}$ \\
\hline Medium price X Depletion & $\begin{array}{l}-1.287 \\
(1.862)\end{array}$ & $\begin{array}{c}-2.559^{* *} \\
(1.171)\end{array}$ & $\begin{array}{c}1.171 \\
(0.844)\end{array}$ \\
\hline Medium price $X$ Placebo & $\begin{array}{c}-1.416^{*} \\
(0.793)\end{array}$ & $\begin{array}{c}-2.578^{* *} \\
(1.040)\end{array}$ & $\begin{array}{c}0.789 \\
(0.754)\end{array}$ \\
\hline Medium price X Sugar & $\begin{array}{c}-1.194 \\
(0.803)\end{array}$ & $\begin{array}{c}-4.321^{* * *} \\
(0.943)\end{array}$ & $\begin{array}{l}2.024^{* *} \\
(0.657)\end{array}$ \\
\hline High price & $\begin{array}{c}-5.764^{* * *} \\
(0.739)\end{array}$ & $\begin{array}{c}-5.550^{* * *} \\
(0.831)\end{array}$ & $\begin{array}{c}-6.157^{* * *} \\
(1.038)\end{array}$ \\
\hline High price $X$ Depletion & $\begin{array}{c}-0.806 \\
(0.738)\end{array}$ & $\begin{array}{c}-2.019^{* *} \\
(1.010)\end{array}$ & $\begin{array}{c}1.264^{*} \\
(0.653)\end{array}$ \\
\hline High price X Placebo & $\begin{array}{c}-1.393^{* *} \\
(0.686)\end{array}$ & $\begin{array}{c}-2.271^{* *} \\
(0.967)\end{array}$ & $\begin{array}{c}0.268 \\
(0.454)\end{array}$ \\
\hline High price $X$ Sugar & $\begin{array}{c}-1.208^{*} \\
(0.686)\end{array}$ & $\begin{array}{c}-3.020^{* * *} \\
(0.883)\end{array}$ & $\begin{array}{l}0.995^{* *} \\
(0.441)\end{array}$ \\
\hline Clusters & 149 & 74 & 75 \\
\hline Observations & 6705 & 3330 & 3375 \\
\hline
\end{tabular}


Table 4: Treatment Effects on Aggregate Utility Parameter Estimates Estimation Sample

\begin{tabular}{|c|c|c|c|}
\hline & All Subjects & Lower-Score & High-Score \\
\hline & (1) & (2) & (3) \\
\hline \multicolumn{4}{|l|}{$\alpha$ (Utility Curvature) } \\
\hline Constant (Baseline) & $\begin{array}{c}0.904 \\
(0.015)\end{array}$ & $\begin{array}{c}0.860 \\
(0.027)\end{array}$ & $\begin{array}{c}0.961 \\
(0.007)\end{array}$ \\
\hline Depletion Effect & $\begin{array}{c}0.028 \\
(0.018)\end{array}$ & $\begin{array}{c}0.058^{*} \\
(0.031)\end{array}$ & $\begin{array}{c}-0.016 \\
(0.013)\end{array}$ \\
\hline Placebo Effect & $\begin{array}{l}0.042^{* *} \\
(0.016)\end{array}$ & $\begin{array}{c}0.087^{* * *} \\
(0.028)\end{array}$ & $\begin{array}{c}-0.014 \\
(0.013)\end{array}$ \\
\hline Sugar Effect & $\begin{array}{c}0.036^{* *} \\
(0.016)\end{array}$ & $\begin{array}{c}0.105^{* * *} \\
(0.028)\end{array}$ & $\begin{array}{c}-0.030^{* * *} \\
(0.011)\end{array}$ \\
\hline \multicolumn{4}{|l|}{$\beta$ (Present Bias) } \\
\hline Constant (Baseline) & $\begin{array}{c}0.979 \\
(0.016)\end{array}$ & $\begin{array}{c}0.949 \\
(0.026)\end{array}$ & $\begin{array}{c}1.002 \\
(0.013)\end{array}$ \\
\hline Depletion Effect & $\begin{array}{c}0.006 \\
(0.018)\end{array}$ & $\begin{array}{c}0.045 \\
(0.027)\end{array}$ & $\begin{array}{l}-0.023 \\
(0.018)\end{array}$ \\
\hline Placebo Effect & $\begin{array}{c}0.004 \\
(0.018)\end{array}$ & $\begin{array}{c}0.031 \\
(0.029)\end{array}$ & $\begin{array}{l}-0.014 \\
(0.018)\end{array}$ \\
\hline Sugar Effect & $\begin{array}{c}0.004 \\
(0.019)\end{array}$ & $\begin{array}{c}0.025 \\
(0.029)\end{array}$ & $\begin{array}{c}-0.016 \\
(0.018)\end{array}$ \\
\hline \multicolumn{4}{|c|}{$r$ (Annual Discount Rate) } \\
\hline Constant (Baseline) & $\begin{array}{c}0.268 \\
(0.106)\end{array}$ & $\begin{array}{c}0.357 \\
(0.225)\end{array}$ & $\begin{array}{c}0.210 \\
(0.068)\end{array}$ \\
\hline Depletion Effect & $\begin{array}{l}-0.140 \\
(0.124)\end{array}$ & $\begin{array}{l}-0.267 \\
(0.256)\end{array}$ & $\begin{array}{l}-0.057 \\
(0.097)\end{array}$ \\
\hline Placebo Effect & $\begin{array}{l}-0.046 \\
(0.121)\end{array}$ & $\begin{array}{l}-0.076 \\
(0.236)\end{array}$ & $\begin{array}{l}-0.076 \\
(0.114)\end{array}$ \\
\hline Sugar Effect & $\begin{array}{l}-0.016 \\
(0.122)\end{array}$ & $\begin{array}{l}-0.219 \\
(0.237)\end{array}$ & $\begin{array}{c}0.109 \\
(0.107)\end{array}$ \\
\hline Clusters & 149 & 74 & 75 \\
\hline Observations & 6705 & 3330 & 3375 \\
\hline
\end{tabular}

Standard Errors in parentheses, clustered by individual. 45 observations (budgets) per cluster. 
Table 5: Treatment Effects on Median Individual Utility Parameter Estimates Estimation Sample

\begin{tabular}{|c|c|c|c|}
\hline & All Subjects & Lower-Score & High-Score \\
\hline & (1) & (2) & (3) \\
\hline \multicolumn{4}{|l|}{$\alpha$ (Utility Curvature) } \\
\hline Constant (Baseline) & $\begin{array}{c}0.958 \\
(0.009)\end{array}$ & $\begin{array}{c}0.940 \\
(0.011)\end{array}$ & $\begin{array}{c}0.974 \\
(0.008)\end{array}$ \\
\hline Depletion Effect & $\begin{array}{c}0.016 \\
(0.010)\end{array}$ & $\begin{array}{c}0.023^{*} \\
(0.013)\end{array}$ & $\begin{array}{c}0.008 \\
(0.014)\end{array}$ \\
\hline Placebo Effect & $\begin{array}{c}0.012 \\
(0.012)\end{array}$ & $\begin{array}{l}0.027^{*} \\
(0.015)\end{array}$ & $\begin{array}{c}0.005 \\
(0.019)\end{array}$ \\
\hline Sugar Effect & $\begin{array}{c}0.010 \\
(0.011)\end{array}$ & $\begin{array}{c}0.039^{* * *} \\
(0.013)\end{array}$ & $\begin{array}{c}-0.011 \\
(0.011)\end{array}$ \\
\hline \multicolumn{4}{|l|}{$\beta$ (Present Bias) } \\
\hline Constant (Baseline) & $\begin{array}{c}0.979 \\
(0.026)\end{array}$ & $\begin{array}{c}0.949 \\
(0.028)\end{array}$ & $\begin{array}{c}1.013 \\
(0.014)\end{array}$ \\
\hline Depletion Effect & $\begin{array}{l}-0.002 \\
(0.027)\end{array}$ & $\begin{array}{c}0.041 \\
(0.030)\end{array}$ & $\begin{array}{c}-0.035^{* *} \\
(0.016)\end{array}$ \\
\hline Placebo Effect & $\begin{array}{c}0.013 \\
(0.026)\end{array}$ & $\begin{array}{c}0.047 \\
(0.030)\end{array}$ & $\begin{array}{l}-0.023 \\
(0.019)\end{array}$ \\
\hline Sugar Effect & $\begin{array}{l}-0.001 \\
(0.029)\end{array}$ & $\begin{array}{c}0.018 \\
(0.037)\end{array}$ & $\begin{array}{l}-0.035^{*} \\
(0.019)\end{array}$ \\
\hline \multicolumn{4}{|c|}{$r$ (Annual Discount Rate) } \\
\hline Constant (Baseline) & $\begin{array}{c}0.323 \\
(0.104)\end{array}$ & $\begin{array}{c}0.490 \\
(0.250)\end{array}$ & $\begin{array}{c}0.323 \\
(0.073)\end{array}$ \\
\hline Depletion Effect & $\begin{array}{c}0.048 \\
(0.143)\end{array}$ & $\begin{array}{c}0.017 \\
(0.285)\end{array}$ & $\begin{array}{c}-0.081 \\
(0.140)\end{array}$ \\
\hline Placebo Effect & $\begin{array}{c}0.105 \\
(0.148)\end{array}$ & $\begin{array}{l}-0.040 \\
(0.272)\end{array}$ & $\begin{array}{c}-0.034 \\
(0.192)\end{array}$ \\
\hline Sugar Effect & $\begin{array}{l}-0.000 \\
(0.130)\end{array}$ & $\begin{array}{c}-0.311 \\
(0.273)\end{array}$ & $\begin{array}{c}0.109 \\
(0.149)\end{array}$ \\
\hline Observations & 104 & 46 & 58 \\
\hline
\end{tabular}


Table 6: Treatment Effect on Early Payment Demand with Meal Time Controls Estimation Sample

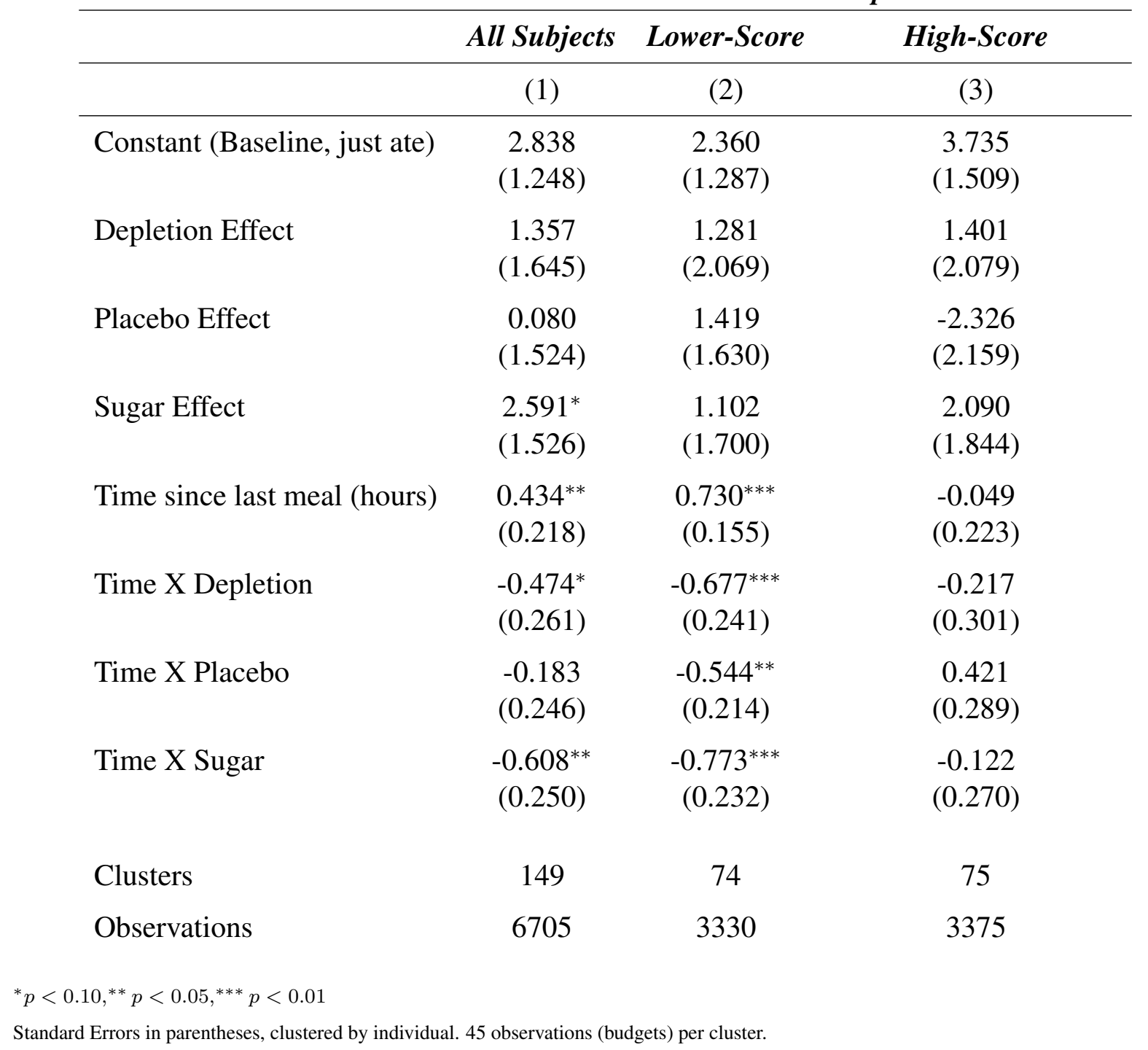


Table 7: Treatment Effect on Early Payment Demand by CRT Score Estimation Sample

\begin{tabular}{lcccc}
\hline & $\boldsymbol{C R T}=\mathbf{0}$ & $\boldsymbol{C R T}=\mathbf{1}$ & $\boldsymbol{C R T = 2}$ & $\boldsymbol{C R T = 3}$ \\
\hline & $(1)$ & $(2)$ & $(3)$ & $(4)$ \\
\hline Constant (Baseline) & 6.916 & 5.061 & 3.039 & 4.654 \\
& $(0.997)$ & $(0.965)$ & $(1.165)$ & $(2.410)$ \\
Depletion Effect & $-3.580^{* *}$ & -1.457 & 0.796 & 1.296 \\
& $(1.405)$ & $(1.635)$ & $(1.345)$ & $(3.015)$ \\
Placebo Effect & $-2.468^{*}$ & 0.251 & 0.096 & -0.726 \\
& $(1.240)$ & $(1.319)$ & $(1.653)$ & $(2.559)$ \\
Sugar Effect & $-2.409^{*}$ & -0.217 & 1.143. & -0.299 \\
& $(1.351)$ & $(1.260)$ & $(1.728)$ & $(2.599)$ \\
Clusters & & & & \\
Observations & 189 & 40 & 40 & 27 \\
& & 1800 & 1800 & 1215
\end{tabular}

${ }^{*} p<0.10,{ }^{* *} p<0.05,{ }^{* * *} p<0.01$

Standard Errors in parentheses, clustered by individual. 45 observations (budgets) per cluster. 


\section{A Appendix for Online Publication}

Table A1: The 45 Choice Sets in the Time Preference Elicitation Task

\section{Parameter}

\begin{tabular}{|c|c|c|c|c|c|c|}
\hline $\begin{array}{l}\text { Choice } \\
\text { number }\end{array}$ & $\begin{array}{c}\text { Early date } \\
t\end{array}$ & $\begin{array}{c}\text { Delay length } \\
k\end{array}$ & $\begin{array}{c}\text { Early value of } \\
1 \text { token } a_{t}\end{array}$ & $\begin{array}{l}\text { Price of an } \\
\text { early Euro }\end{array}$ & $\begin{array}{c}\text { Annual intrest } \\
\text { rate } \%\end{array}$ & $\begin{array}{l}\text { Maximum early } \\
\text { payoff }\end{array}$ \\
\hline 1 & 0 & 5 & 0.97 & 1.03 & 36 & 15.52 \\
\hline 2 & 0 & 5 & 0.95 & 1.05 & 65 & 15.20 \\
\hline 3 & 0 & 5 & 0.93 & 1.08 & 100 & 14.88 \\
\hline 4 & 0 & 5 & 0.91 & 1.10 & 141 & 14.56 \\
\hline 5 & 0 & 5 & 0.89 & 1.12 & 189 & 14.24 \\
\hline 6 & 5 & 10 & 0.97 & 1.03 & 17 & 15.52 \\
\hline 7 & 5 & 10 & 0.94 & 1.06 & 36 & 15.04 \\
\hline 8 & 5 & 10 & 0.91 & 1.10 & 59 & 14.56 \\
\hline 9 & 5 & 10 & 0.88 & 1.14 & 85 & 14.08 \\
\hline 10 & 5 & 10 & 0.85 & 1.18 & 116 & 13.60 \\
\hline 11 & 15 & 15 & 0.97 & 1.03 & 11 & 15.52 \\
\hline 12 & 15 & 15 & 0.93 & 1.08 & 28 & 14.88 \\
\hline 13 & 15 & 15 & 0.89 & 1.12 & 47 & 14.24 \\
\hline 14 & 15 & 15 & 0.85 & 1.18 & 70 & 13.60 \\
\hline 15 & 15 & 15 & 0.81 & 1.23 & 96 & 12.96 \\
\hline 16 & 0 & 10 & 0.98 & 1.02 & 11 & 15.68 \\
\hline 17 & 0 & 10 & 0.93 & 1.08 & 44 & 14.88 \\
\hline 18 & 0 & 10 & 0.88 & 1.14 & 85 & 14.08 \\
\hline 19 & 0 & 10 & 0.83 & 1.20 & 139 & 13.28 \\
\hline 20 & 0 & 10 & 0.78 & 1.28 & 208 & 12.48 \\
\hline 21 & 5 & 15 & 0.98 & 1.02 & 7 & 15.68 \\
\hline 22 & 5 & 15 & 0.92 & 1.09 & 32 & 14.72 \\
\hline 23 & 5 & 15 & 0.86 & 1.16 & 64 & 13.76 \\
\hline 24 & 5 & 15 & 0.80 & 1.25 & 103 & 12.80 \\
\hline 25 & 5 & 15 & 0.74 & 1.35 & 154 & 11.84 \\
\hline 26 & 15 & 5 & 0.98 & 1.02 & 23 & 15.68 \\
\hline 27 & 15 & 5 & 0.94 & 1.06 & 82 & 15.04 \\
\hline 28 & 15 & 5 & 0.90 & 1.11 & 164 & 14.40 \\
\hline 29 & 15 & 5 & 0.86 & 1.16 & 278 & 13.76 \\
\hline 30 & 15 & 5 & 0.82 & 1.22 & 432 & 13.12 \\
\hline 31 & 0 & 15 & 0.99 & 1.01 & 4 & 15.84 \\
\hline 32 & 0 & 15 & 0.91 & 1.10 & 37 & 14.56 \\
\hline 33 & 0 & 15 & 0.83 & 1.20 & 83 & 13.28 \\
\hline 34 & 0 & 15 & 0.75 & 1.33 & 144 & 12.00 \\
\hline 35 & 0 & 15 & 0.67 & 1.49 & 231 & 10.72 \\
\hline 36 & 5 & 5 & 0.99 & 1.01 & 11 & 15.84 \\
\hline 37 & 5 & 5 & 0.93 & 1.08 & 100 & 14.88 \\
\hline 38 & 5 & 5 & 0.87 & 1.15 & 246 & 13.92 \\
\hline 39 & 5 & 5 & 0.81 & 1.23 & 479 & 12.96 \\
\hline 40 & 5 & 5 & 0.75 & 1.33 & 845 & 12.00 \\
\hline 41 & 15 & 10 & 0.99 & 1.01 & 5 & 15.84 \\
\hline 42 & 15 & 10 & 0.92 & 1.09 & 51 & 14.72 \\
\hline 43 & 15 & 10 & 0.85 & 1.18 & 116 & 13.60 \\
\hline 44 & 15 & 10 & 0.78 & 1.28 & 208 & 12.48 \\
\hline 45 & 15 & 10 & 0.71 & 1.41 & 339 & 11.36 \\
\hline
\end{tabular}




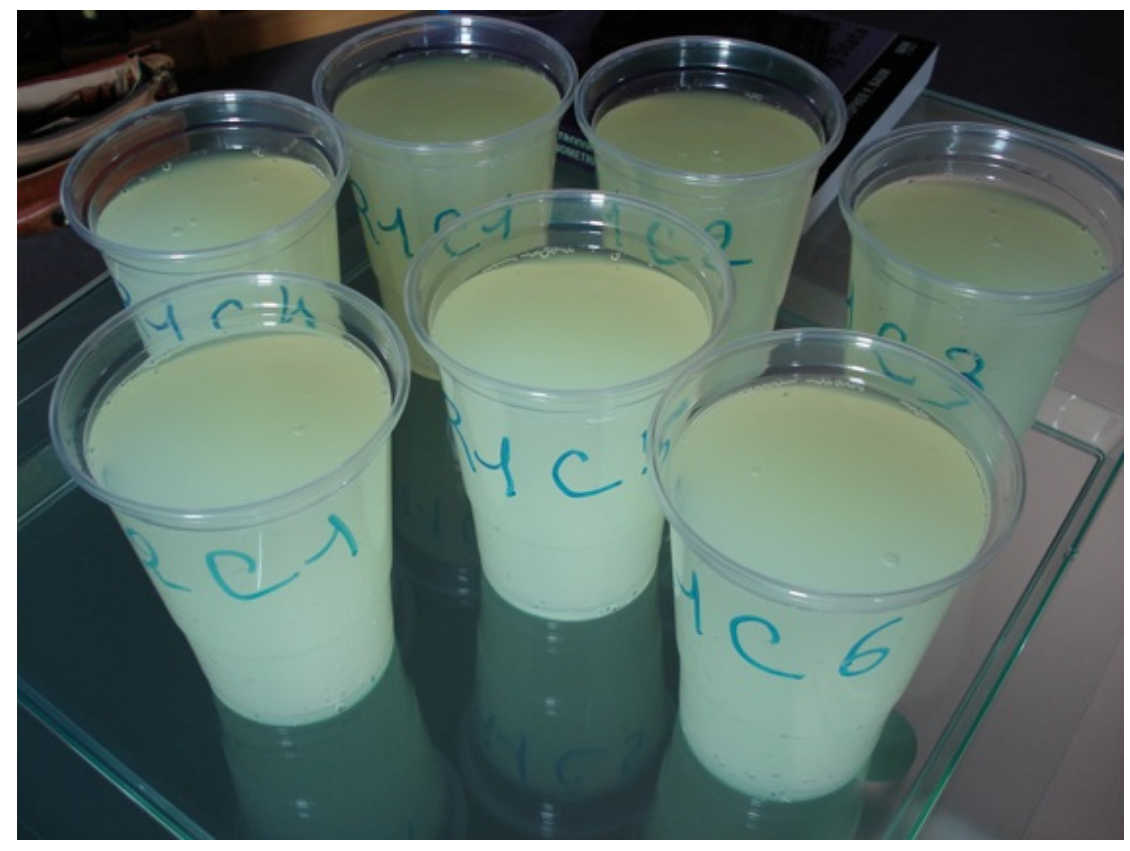

Figure A1: Glasses Containing either the Placebo or the Sugared Beverage 

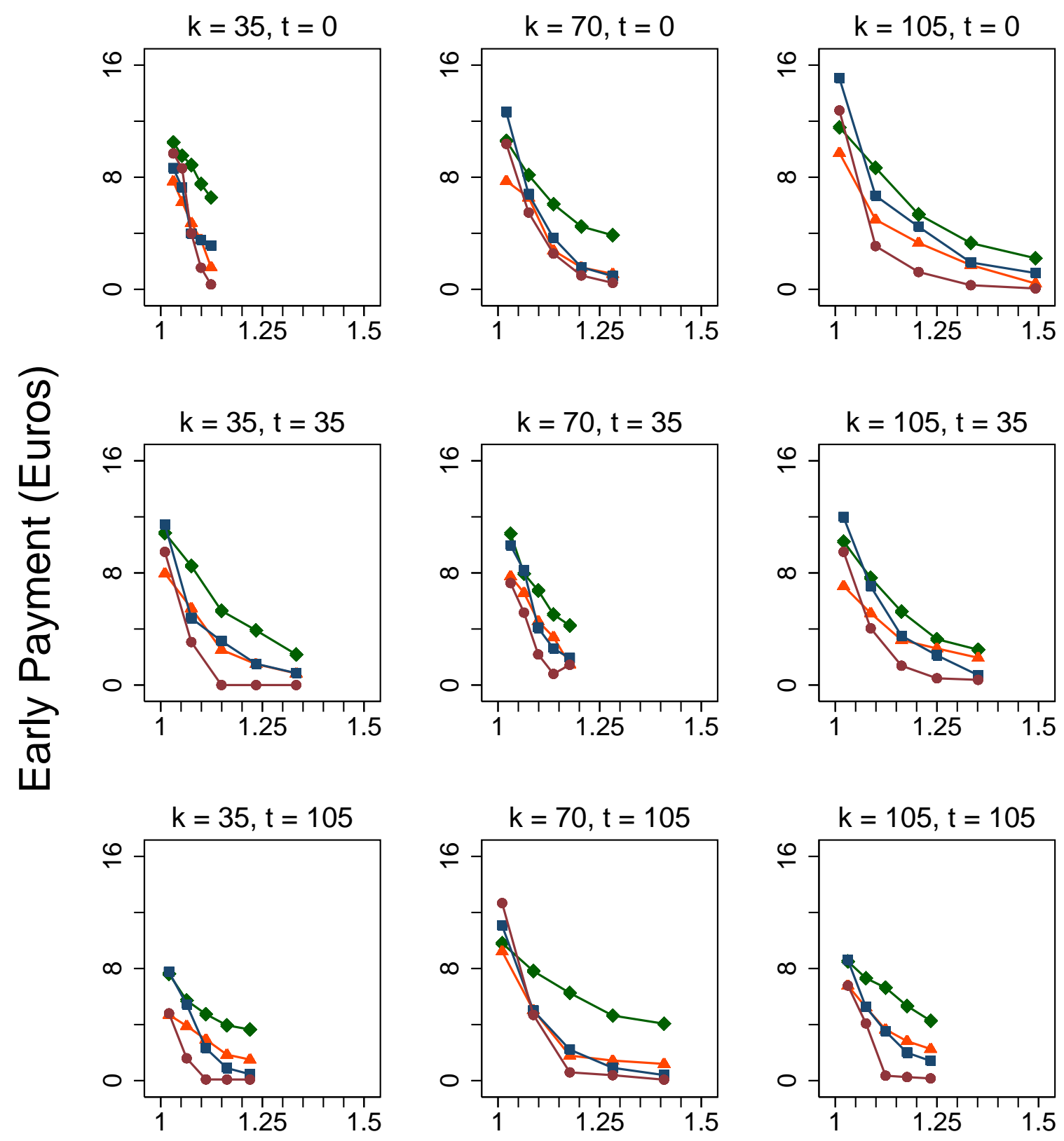

\section{Price of an Early Euro (in Late Euros)}

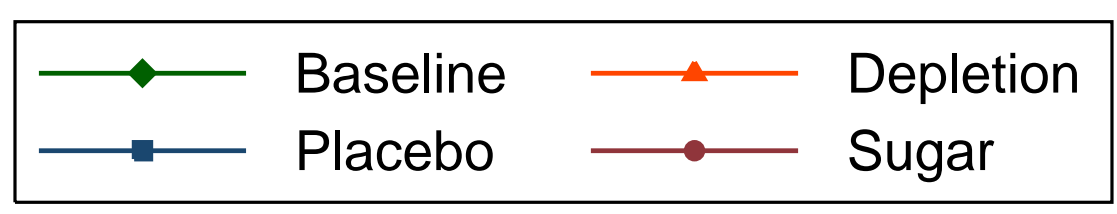

Figure A2: Demand Functions by Treatment, Lower-Score Sample 

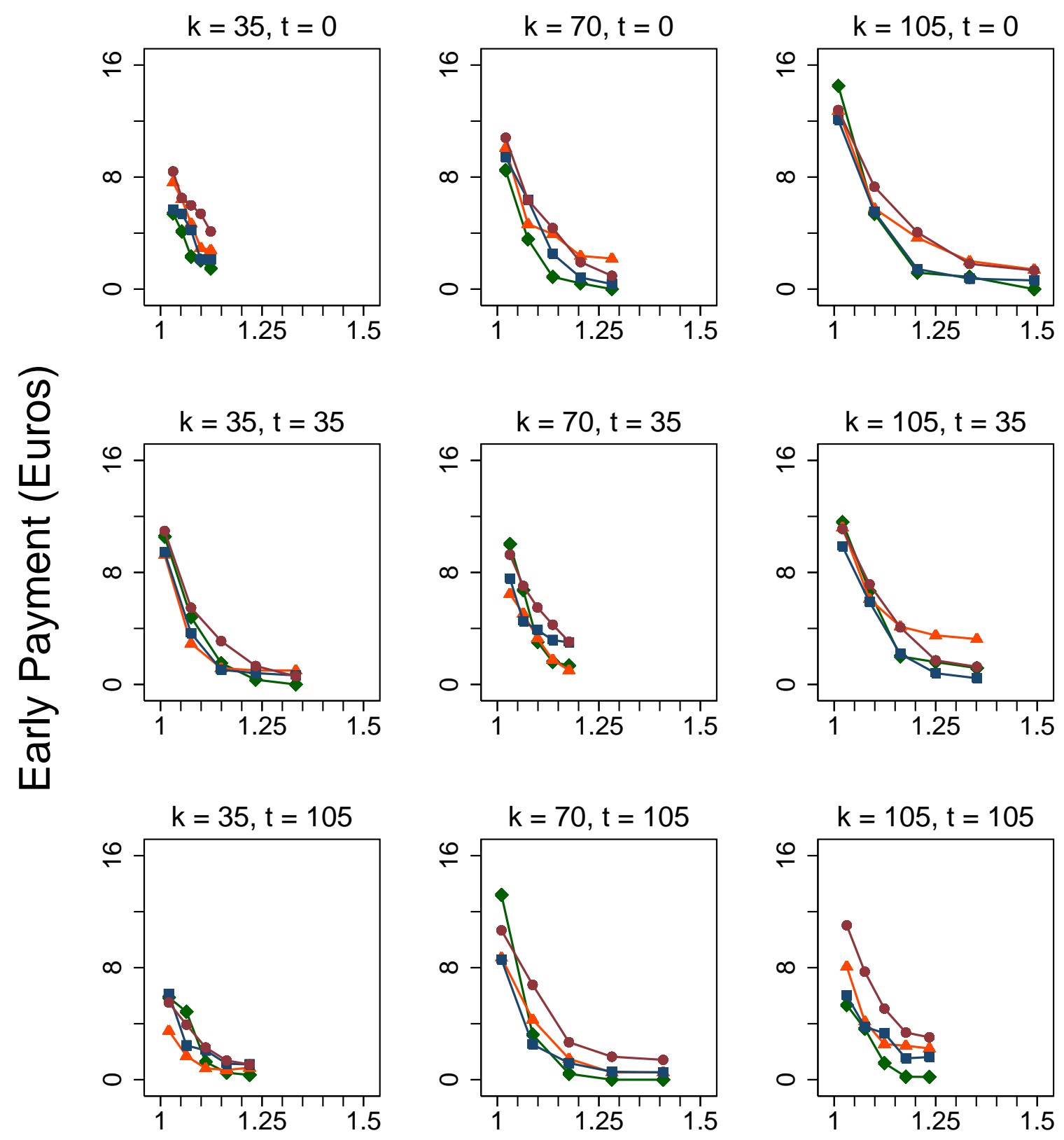

\section{Price of an Early Euro (in Late Euros)}

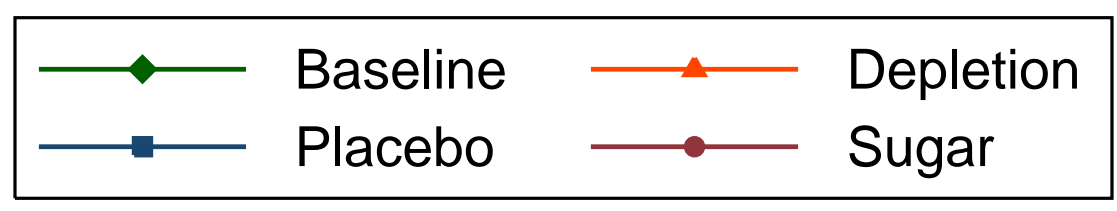

Figure A3: Demand Functions by Treatment, High-Score Sample 
Table A2: Treatment Effect on Early Payment Demand with Mood Controls

\begin{tabular}{|c|c|c|c|}
\hline & \multicolumn{3}{|c|}{ Estimation Sample } \\
\hline & All Subjects & Lower-Score & High-Score \\
\hline & $(1)$ & (2) & (3) \\
\hline Constant (Baseline, neutral mood) & $\begin{array}{c}5.168 \\
(2.506)\end{array}$ & $\begin{array}{c}7.898 \\
(3.551)\end{array}$ & $\begin{array}{c}2.638 \\
(2.112)\end{array}$ \\
\hline Placebo Effect & $\begin{array}{c}-1.144 \\
(0.834)\end{array}$ & $\begin{array}{l}-1.922 \\
(1.163)\end{array}$ & $\begin{array}{c}-0.412 \\
(0.998)\end{array}$ \\
\hline Sugar Effect & $\begin{array}{c}-0.878 \\
(0.847)\end{array}$ & $\begin{array}{c}-3.407^{* * *} \\
(1.120)\end{array}$ & $\begin{array}{c}1.567^{*} \\
(0.900)\end{array}$ \\
\hline Mood ( -5 to 5 scale) & $\begin{array}{c}0.046 \\
(0.438)\end{array}$ & $\begin{array}{l}-0.260 \\
(0.598)\end{array}$ & $\begin{array}{c}0.160 \\
(0.424)\end{array}$ \\
\hline Mood X Placebo & $\begin{array}{c}-0.383 \\
(0.539)\end{array}$ & $\begin{array}{c}0.381 \\
(0.754)\end{array}$ & $\begin{array}{c}-1.008^{*} \\
(0.586)\end{array}$ \\
\hline Mood X Sugar & $\begin{array}{c}-0.141 \\
(0.527)\end{array}$ & $\begin{array}{c}0.648 \\
(0.679)\end{array}$ & $\begin{array}{c}-0.500 \\
(0.558)\end{array}$ \\
\hline Clusters & 109 & 55 & 54 \\
\hline Observations & 4905 & 2475 & 2430 \\
\hline
\end{tabular}

${ }^{*} p<0.10,{ }^{* *} p<0.05,{ }^{* * *} p<0.01$

Standard Errors in parentheses, clustered by individual. 45 observations (budgets) per cluster. Mood is elicited on a 1-10 scale. We renormalize to -5 to 5 such that treatment effect estimates refer to neutral mood. 
Table A3: Treatment Effect on Early Payment Demand with Drink Enjoyment Controls Estimation Sample

\begin{tabular}{|c|c|c|c|}
\hline & All Subjects & Lower-Score & High-Score \\
\hline & (1) & (2) & (3) \\
\hline Constant (Baseline, neutral enjoyment) & $\begin{array}{c}5.408 \\
(0.674)\end{array}$ & $\begin{array}{c}6.491 \\
(0.896)\end{array}$ & $\begin{array}{c}3.422 \\
(0.681)\end{array}$ \\
\hline Placebo Effect & $\begin{array}{c}-1.258 \\
(0.809)\end{array}$ & $\begin{array}{c}-1.852^{*} \\
(1.037)\end{array}$ & $\begin{array}{c}0.004 \\
(1.021)\end{array}$ \\
\hline Sugar Effect & $\begin{array}{c}-1.054 \\
(0.803)\end{array}$ & $\begin{array}{c}-3.344^{* * *} \\
(1.107)\end{array}$ & $\begin{array}{c}1.385 \\
(0.862)\end{array}$ \\
\hline Placebo X Enjoyment (-5 to 5 scale) & $\begin{array}{c}-0.231 \\
(0.160)\end{array}$ & $\begin{array}{l}-0.162 \\
(0.172)\end{array}$ & $\begin{array}{l}-0.318 \\
(0.277)\end{array}$ \\
\hline Sugar X Enjoyment (-5 to 5 scale) & $\begin{array}{c}0.296^{*} \\
(0.172)\end{array}$ & $\begin{array}{c}0.072 \\
(0.191)\end{array}$ & $\begin{array}{c}0.373^{*} \\
(0.196)\end{array}$ \\
\hline Clusters & 109 & 55 & 54 \\
\hline Observations & 4905 & 2475 & 2430 \\
\hline \multicolumn{4}{|l|}{$p<0.10,{ }^{* *} p<0.05,{ }^{* * *} p<0.01$} \\
\hline Standard Errors in parentheses, clustered by individual. 45 ob & vations (budgets) per & luster. Enjoyment is e & a 1-10 scale. We r \\
\hline
\end{tabular}


Table A4: Treatment Effects on Probability of Corner Solution Choice Marginal Effects from Multinomial Logit Model

Estimation Sample

\begin{tabular}{lcccccc}
\hline & \multicolumn{2}{c}{ All Subjects } & \multicolumn{2}{c}{ Lower-Score } & \multicolumn{2}{c}{ High-Score } \\
\hline Corner Choice: & Sooner & Later & Sooner & Later & Sooner & Later \\
& $(1)$ & $(2)$ & $(3)$ & $(4)$ & $(5)$ & $(6)$ \\
\hline Constant (Basline) & 0.242 & 0.472 & 0.287 & 0.344 & 0.161 & 0.706 \\
& $(0.046)$ & $(0.060)$ & $(0.066)$ & $(0.072)$ & $(0.038)$ & $(0.069)$ \\
Depletion Effect & -0.063 & $0.149^{*}$ & $-0.142^{*}$ & $0.217^{* *}$ & 0.049 & -0.030 \\
& $(0.057)$ & $(0.078)$ & $(0.084)$ & $(0.108)$ & $(0.058)$ & $(0.089)$ \\
Placebo Effect & -0.055 & 0.111 & -0.077 & $0.179^{*}$ & -0.009 & -0.033 \\
& $(0.054)$ & $(0.080)$ & $(0.075)$ & $(0.096)$ & $(0.059)$ & $(0.111)$ \\
Sugar Effect & -0.061 & 0.060 & $-1.156^{* *}$ & $0.307^{* * *}$ & 0.040 & $-0.217^{* *}$ \\
& $(0.054)$ & $(0.078)$ & $(0.071)$ & $(0.105)$ & $(0.053)$ & $(0.091)$
\end{tabular}

$\begin{array}{llll}\text { Clusters } & 149 & 74 & 75\end{array}$

$\begin{array}{lll}\text { Observations } & 6705 & 3330\end{array}$

${ }^{*} p<0.10,{ }^{* *} p<0.05,{ }^{* * *} p<0.01$

Standard Errors in parentheses, clustered by individual. 45 observations (budgets) per cluster. The multinomial logit specification estimates the effect of our treatments on the probability of choosing either the sooner or later corner solution, with respect to an interior choice (all pooled). This table presents the marginal effects of changing the treatment indicators from 0 to 1 , holding the other indicators constant at 0 . 


\section{Instructions}

You are about to participate in an experimental session on decision-making.

The session consists of several parts. You will receive the instructions for each part after the previous part has been completed.

\section{Part 1}

Your computer screen will display a number of questions. We thank you for answering these questions with care.

Once all participants will have answered these questions, we will distribute glasses of a beverage that we will invite you to drink. Please do not drink the beverage before being expressly invited to do it.

Next, you will have to answer a few questions.

After you have answered these questions, you will have to wait for the next part. During this rest period, you are allowed to read books, newspapers or magazines. During this part and throughout the session, it is not allowed to talk to the other participants. 


\section{Part 2}

\section{Your decisions}

In this part, you will be asked to make a series of choices between payments you can receive at different dates. On each of nine decision screens, you will decide how to divide your payment for the experiment between two dates: an 'early' date and a 'late' date.

Altogether, you will make a total of 45 choices on the nine decision screens. These decision screens will be displayed in a random order. You will have the following options for payment dates:

Decide between payment today and payment in $\underline{5 \text { weeks }}$

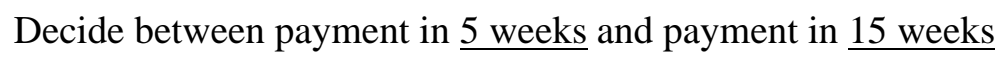

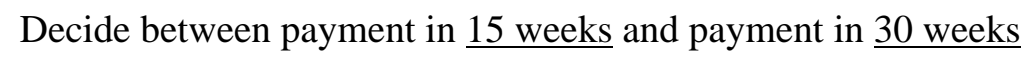

Decide between payment today and payment in 10 weeks

Decide between payment in $\underline{5 \text { weeks }}$ and payment in $\underline{20 \text { weeks }}$

Decide between payment in $\underline{15 \text { weeks }}$ and payment in $\underline{20 \text { weeks }}$

Decide between payment today and payment in $\underline{15 \text { weeks }}$

Decide between payment in $\underline{5 \text { weeks }}$ and payment in $\underline{10 \text { weeks }}$

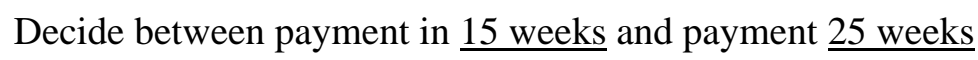

On each decision screen, we will provide you with the exact calendar dates of the above payments, so you know exactly which decision you are making. Today's date appears in green, the early payment date appears in blue and the late payment date appears in red.

You will be given 16 tokens to divide in each choice, but the value of a token changes from choice to choice. The real money payments associated with your token choices will be automatically calculated for you to see as you make your decisions.

To make your decisions, you can enter a number for the early payment (or the late payment) and move the up and down arrows. The box corresponding to the late payment (or the early payment, respectively) will be automatically updated by a number indicating the difference between 16 and the tokens assigned to the other date of payment.

Once you have completed a set of five decisions, you must press the "Validate" button to move to the next decision screen.

Below is an example of a decision screen. 


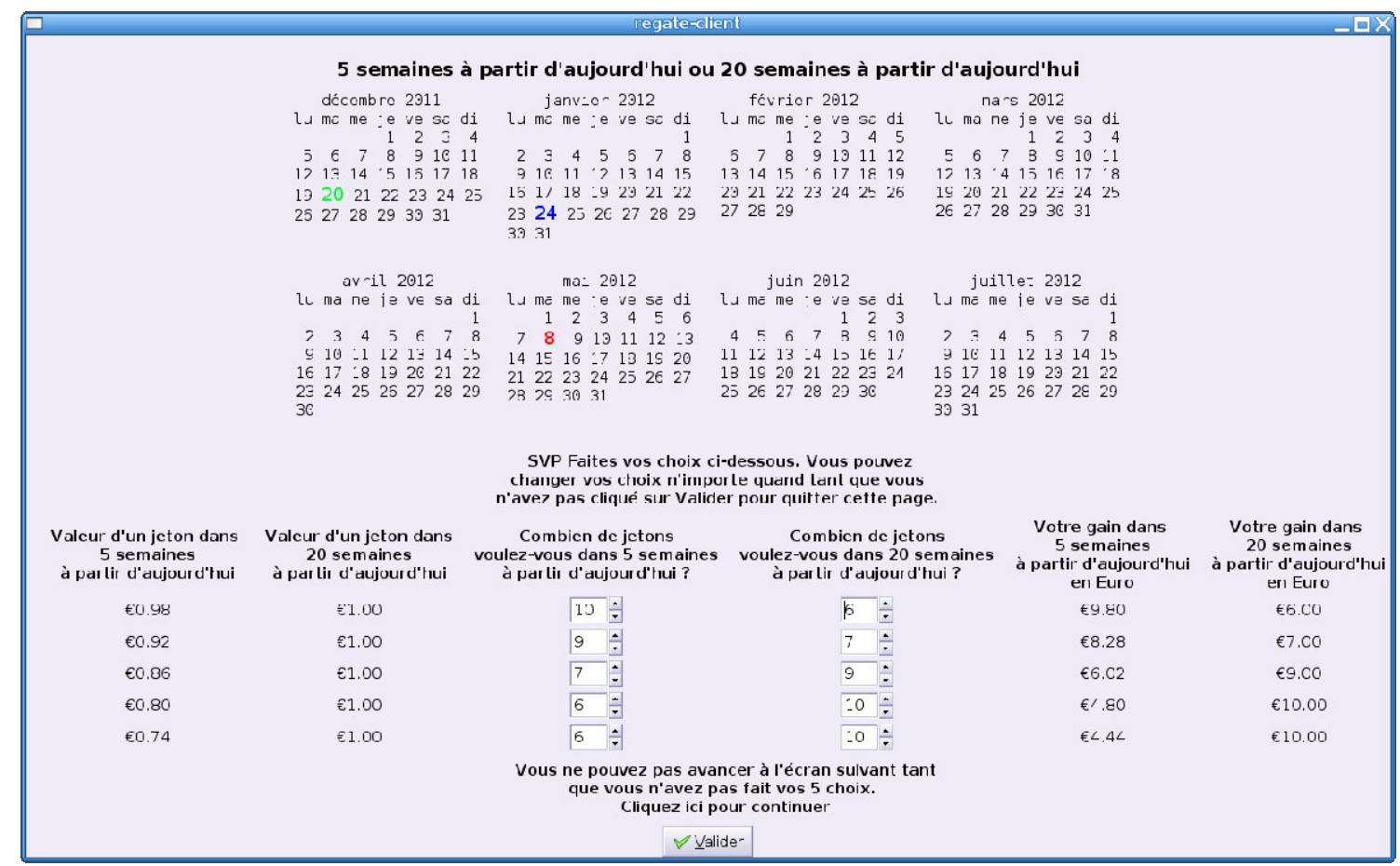

\section{Your payment}

At the end of the session, the computer program will randomly select one of the 45 decisions you made to be your earnings from participating in this experiment.

In addition, you will receive a €5 participation payment that will be split up into two payments of €2.50: one to go along with your earnings at the early and late dates associated with the randomly selected decision.

This means that you will not be paid in cash today. You will be paid by checks that will be mailed to you at the address you will indicate on the envelopes on your desk. We will mail the envelopes at the dates corresponding to the randomly selected decision.

For example, if the selected decision indicates that you have chosen $x$ tokens today and $y$ tokens in 10 weeks, we will mail the first check today and the second check in 10 weeks from today.

Remember that each decision could be the one that counts! Treat each decision as if it could be the one that determines your payment.

If you have any question on these instructions, please raise your hand and we will answer your questions in private. 


\section{Part 3}

In this part, you will be presented with a series of color words (black, blue, yellow, green, red). These words will appear in different colors, sometimes matching the word (e.g., the word blue, written in blue), and sometimes not matching the word (e.g., the word blue, written in red).

Your job is to indicate, as quickly and accurately as possible, the color in which the word is written, whether or not that matches the word itself. Click the button that matches the color of the word. Try not to pay attention to the word, but just the color.

This task will last for six minutes.

Example :

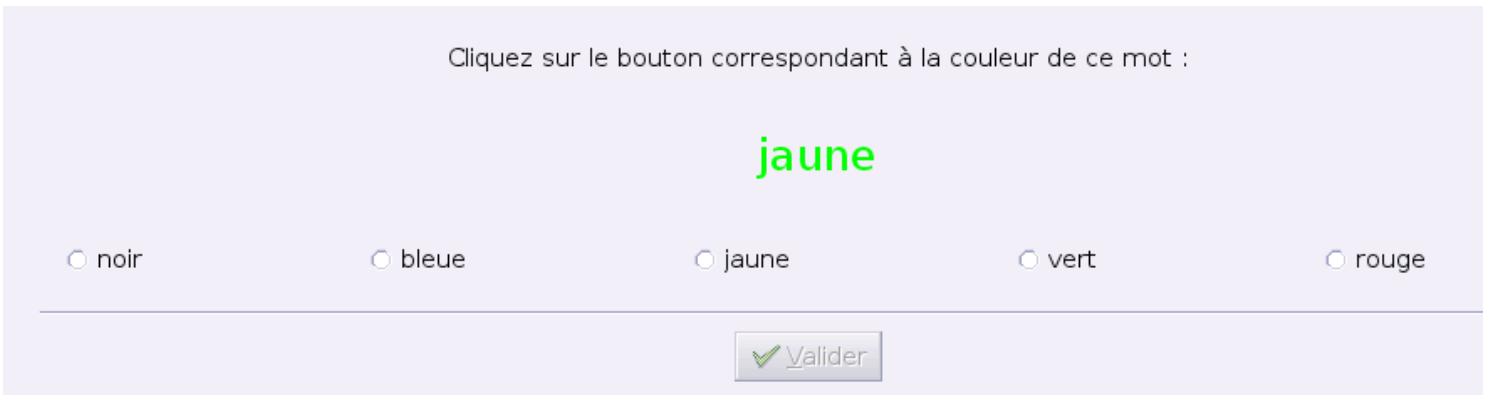

In this example, the correct answer is « green ». 